\title{
Room Temperature Metal Hydrides for Stationary and Heat Storage Applications: A Review
}

\author{
Poojan Modit and Kondo-Francois Aguey-Zinsou*t \\ MERLin, School of Chemical Engineering, The University of New South Wales, Sydney, NSW, Australia
}

Hydrogen has been long known to provide a solution toward clean energy systems. With this notion, many efforts have been made to find new ways of storing hydrogen. As a result, decades of studies has led to a wide range of hydrides that can store hydrogen in a solid form. Applications of these solid-state hydrides are well-suited to stationary applications. However, the main challenge arises in making the selection of the Metal Hydrides $(\mathrm{MH})$ that are best suited to meet application requirements. Herein,

OPEN ACCESS

Edited by:

Daniele Mirabile Gattia, Energy and Sustainable Economic

Development (ENEA), Italy

Reviewed by:

Terry David Humphries,

Curtin University, Australia

Giovanni Capurso,

Helmholtz Centre for Materials and Coastal Research (HZG)

Germany

Mykhaylo Lototskyy,

University of the Western Cape, South Africa

${ }^{*}$ Correspondence:

Kondo-Francois Aguey-Zinsou f.aguey@unsw.edu.au

tThese authors have contributed equally to this work

Specialty section:

This article was submitted to Hydrogen Storage and Production, a section of the journal Frontiers in Energy Research

Received: 11 October 2020 Accepted: 15 March 2021

Published: 09 April 2021

Citation:

Modi P and Aguey-Zinsou K-F (2021) Room Temperature Metal Hydrides for Stationary and Heat

Storage Applications: A Review.

Front. Energy Res. 9:616115. doi: 10.3389/fenrg.2021.616115 we discuss the current state-of-art in controlling the properties of room temperature (RT) hydrides suitable for stationary application and their long term behavior in addition to initial activation, their limitations and emerging trends to design better storage materials. The hydrogen storage properties and synthesis methods to alter the properties of these $\mathrm{MH}$ are discussed including the emerging approach of high-entropy alloys. In addition, the integration of intermetallic hydrides in vessels, their operation with fuel cells and their use as thermal storage is reviewed.

Keywords: hydrogen storage, metal hydrides, stationary application, thermal storage, hydrogen tanks

\section{INTRODUCTION}

The decreasing cost of renewable energy is providing a path toward sustainable energy systems. However, the intermittency of renewables remains a major limitation. In this context, batteries have gained interest as a potential energy storage solution but the amount of possible stored energy is rather limited by current battery chemistries. In comparison, hydrogen $\left(\mathrm{H}_{2}\right)$ can provide a solution to store renewable energy with high density. $\mathrm{H}_{2}$ is the lightest element in the universe. It has a high energy density per unit mass $\left(142 \mathrm{MJ} \mathrm{kg}-1\right.$ ) but has a very low volumetric density of $11 \mathrm{~m}^{3} \mathrm{~kg}^{-1}$ at ambient temperature and atmospheric pressure (Züttel, 2003).

Hydrogen for stationary applications is commonly recognized as a potential power-to-power solution through the integration of electrolysers, $\mathrm{H}_{2}$ storage tanks and fuel-cell stacks. In this case, using hydrogen for seasonal storage provides added benefit for decoupling high peak power demand from steady flow of energy in relation to batteries (Parra et al., 2019). However, owing its versatility, $\mathrm{H}_{2}$ once produced can also enable paths toward power to gas, gas-to-gas $\left(\mathrm{H}_{2}\right.$ refueling), gas-to-heat ( $\mathrm{H}_{2}$ combustion), heat-to-gas (use of the thermal energy released upon $\mathrm{H}_{2}$ gas storage) (Parra et al., 2019). Recently, increasing trends have been observed toward the installation of power-to-gas systems (Figure 1), and this suggests a rise in the production of $\mathrm{H}_{2}$ gas worldwide from renewables. To date, the storage of $\mathrm{H}_{2}$ is often achieved by compressing $\mathrm{H}_{2}$ and this remains the preferred solution owing to the maturity and simplicity of the technology. However, the storage of $\mathrm{H}_{2}$ can also be achieved by liquefaction or as solid state with Metal Hydrides (MH). Hydrogen liquefaction is a very energy intensive process with $30 \%$ of the energy loss through the liquefaction process (von Helmolt and Eberle, 2007). In comparison, 


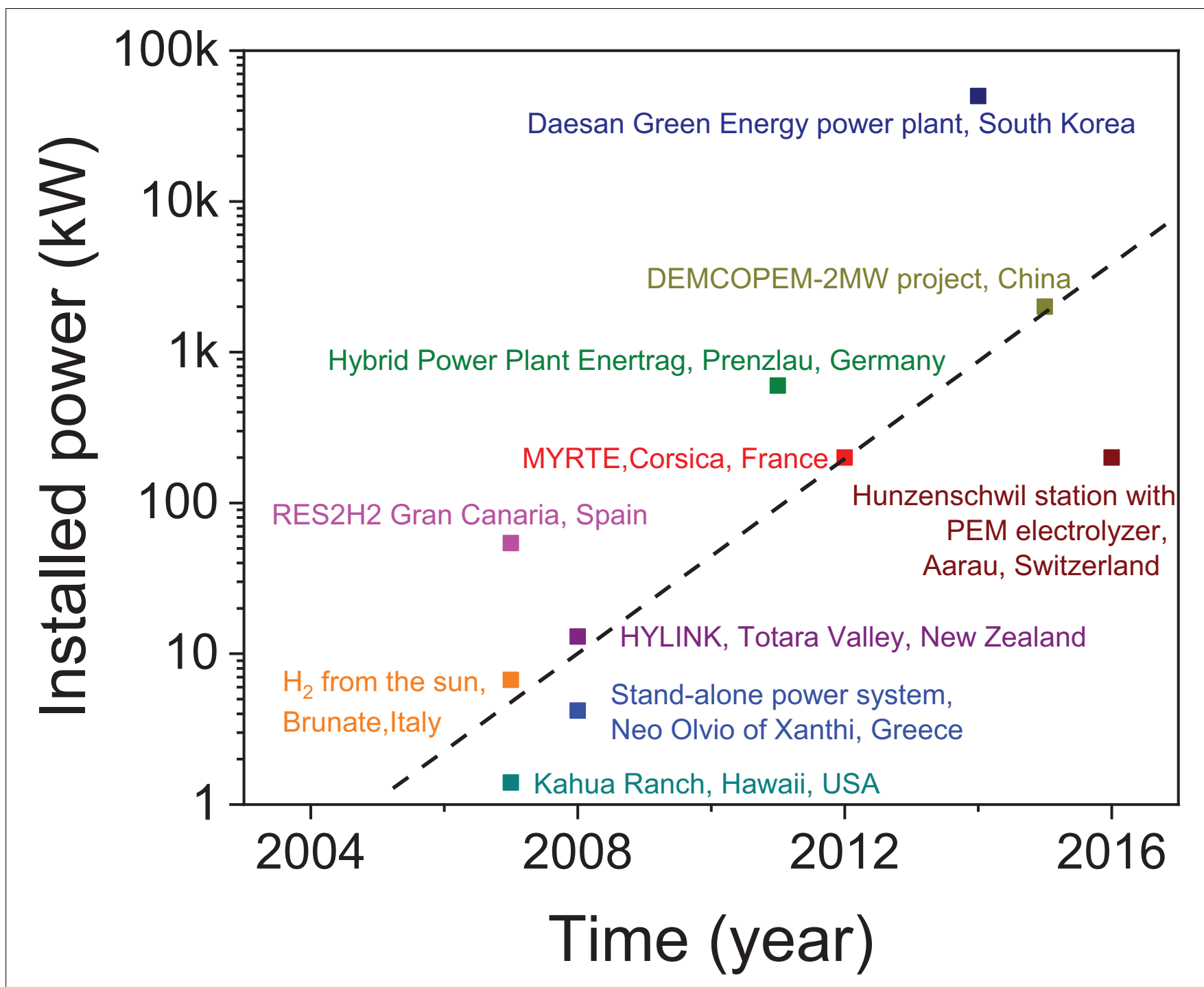

FIGURE 1 | In-operation power-plants producing hydrogen from electricity (Ipsakis et al., 2009; Schoenung, 2010; Ziogou et al., 2011; Darras et al., 2012; Gahleitner, 2013; Fuel Cells Bulletin, 2014, 2016a,b, 2018a,b).

storage tanks using solid state hydrogen materials have the potential to store hydrogen at much higher volumetric densities than compressed and liquefied hydrogen (Table 1), while minimizing the safety risk associated with high pressure hydrogen (Züttel et al., 2010; Lototskyy et al., 2017).

Abbreviations: $\Delta \mathrm{H}^{\theta}$, enthalpy of formation of hydride; $\Delta \mathrm{S}^{\theta}$, entropy of formation of hydride; $\Delta \mathrm{G}_{\text {mix }}$, change in gibbs free energy of the alloy elements; $\Delta \mathrm{H}_{\text {mix }}$, change in enthalpy from alloy elements; $\Delta \mathrm{S}_{\text {mix }}$, configurational entropy of alloy elements; BCC, body centered cubic structure; $\mathrm{dHCP}$, double hexagonal closed packed structure; $E_{a}$, activation energy; FCC, face centered cubic structure; HCP, hexagonal closest packed structure; $\mathrm{K}_{\text {eff }}$, effective thermal conductivity ( $\left.\mathrm{W} \mathrm{m}^{-1} \mathrm{~K}^{-1}\right) ; \mathrm{P}_{\text {eq }}$, equilibrium plateau pressure; PCT, pressure-composition temperature; $\dot{Q}_{m}$, heat flux for the change in temperature of the reactor shell and metal hydride bed $\left(\mathrm{J} \mathrm{s}^{-1}\right) ; \dot{Q}_{\text {reac }}$, energy produced/consumed in solid/gas reaction $\left(\mathrm{J} \mathrm{s}^{-1}\right) ; \dot{Q}_{H_{2}}$, energy transferred in and out of reactor with the $\mathrm{H}_{2}$ gas $\left(\mathrm{J} \mathrm{s}^{-1}\right) ; \dot{Q}_{W}$, Energy transferred in and out of reactor with the heating and cooling of water ( $J$ $\left.\mathrm{s}^{-1}\right)$; R, Universal gas constant (8.314 $\left.\mathrm{J} \mathrm{mol}^{-1} \mathrm{~K}^{-1}\right)$; RE, Rare-earth metal; RT, Room temperature
Although MH have been known and studied for more than four decades (Van Vucht et al., 1970), no consensus has been reached on the optimum metal hydride to be used for hydrogen storage in stationary applications. This is because of the wide range of possible stationary applications resulting in diverse requirements in terms of hydrogen release/absorption rates, pressure and temperature operation of the metal hydride tank.

TABLE 1 | Hydrogen density comparison at system level and is the theoretical limit of the material in parenthesis (Züttel et al., 2010).

Forms of hydrogen storage

Volumetric hydrogen density ( $k \mathrm{H}_{2} \mathrm{~m}^{-3}$ system)

Compressed hydrogen at $25^{\circ} \mathrm{C}$ and $50 \mathrm{MPa}$

27

Liquefied hydrogen at $-253^{\circ} \mathrm{C}$ and $0.1 \mathrm{MPa}$

40 (71)

Metal hydride at $25^{\circ} \mathrm{C}$ and $3 \mathrm{MPa}$ 
TABLE 2 | Estimated targets for stationary applications.

\begin{tabular}{lcc}
\hline Properties & Values & Units \\
\hline Hydrogen capacity & $>2$ & wt\% \\
Enthalpy $\left|\Delta \mathrm{H}^{\theta}\right|$ & $10-60$ & $\mathrm{~kJ} \mathrm{~mol}^{-1} \mathrm{H}$ \\
Activation method & $\leq 3$ cycles at $25^{\circ} \mathrm{C}$ and $3 \mathrm{MPa}$ & \\
Absorption-desorption kinetics & $\leq 3$ & $\mathrm{~min}$ \\
Plateau pressure at $-40^{\circ} \mathrm{C}$ & $>0.1$ (above 1 atm) & $\mathrm{MPa}$ \\
Plateau pressure at $100^{\circ} \mathrm{C}$ & $<3$ & $\mathrm{MPa}$ \\
Cycle stability with $<30 \%$ & 10,000 & $\mathrm{cycles}$ \\
capacity loss & & \\
\hline
\end{tabular}

For example, in the case of power-to-power systems, short-term ramp-up and down to smooth-out the effects of voltage sags and rapid changes in renewable energy generation requires very fast responding $\mathrm{MH}$, i.e., fast $\mathrm{H}_{2}$ desorption kinetics. In contrast, for seasonal storage, very cheap $\mathrm{MH}$ with a very high $\mathrm{H}_{2}$ density for the bulk storage of renewable are considered more attractive. Upon the selection of appropriate hydride materials, several other important parameters should also be considered. These include the ease of activation of the hydride material toward hydrogen uptake/release, its uptake/discharge $\mathrm{H}_{2}$ kinetics, the $\mathrm{H}_{2}$ hysteresis effects (dictating the pressure for hydrogen uptake and release), the heat of formation of the hydride (as this will involve additional heat management issues controlling the rate of $\mathrm{H}_{2}$ uptake/release and thus the overall efficiency), the $\mathrm{H}_{2}$ cyclic stability and cycle life, safety associated with the hydride production, handling and operation, and its sensitivity to gas impurities as this will affect the practical $\mathrm{H}_{2}$ storage capacity (Sandrock, 1999; Lototskyy et al., 2017). Taking this into consideration, we foresee a range of targets for hydride materials for stationary application in relation to renewable energy storage. These targets are summarized in Table 2 considering that only room temperature (RT) hydrides are relevant, i.e., no additional heat is needed to facilitate the uptake or release of hydrogen as to maximize the overall efficiency. This should be accompanied by rapid rates of $\mathrm{H}_{2}(<3 \mathrm{~min})$ uptake/release at the material level across a wide range of temperatures (from 50 to $-40^{\circ} \mathrm{C}$ ) that will vary depending on the location of the stationary system. From our views, relevant $\mathrm{MH}$ should also operate within a limited pressure range of 3 to $0.1 \mathrm{MPa}$ across the temperature window state above so as to reduce the reliance on additional $\mathrm{H}_{2}$ compressors and ensure adequate $\mathrm{H}_{2}$ pressure is fed to the fuel cell. In addition, such stationary $\mathrm{MH}$ should also be capable of $>10,000$ cycles with less than $30 \%$ capacity loss. This would be possible when the material undergoes minimum phase segregation or oxidation upon $\mathrm{H}_{2}$ cycling.

The ideal scenario for stationary application would require $\mathrm{MH}$ to have high volumetric and gravimetric hydrogen densities. As shown in Figure 2, complex hydrides such as $\mathrm{Mg}\left(\mathrm{BH}_{4}\right)_{2}$, $\mathrm{Al}\left(\mathrm{BH}_{4}\right)_{2}$ and $\mathrm{LiBH}_{4}$ are capable of meeting high density

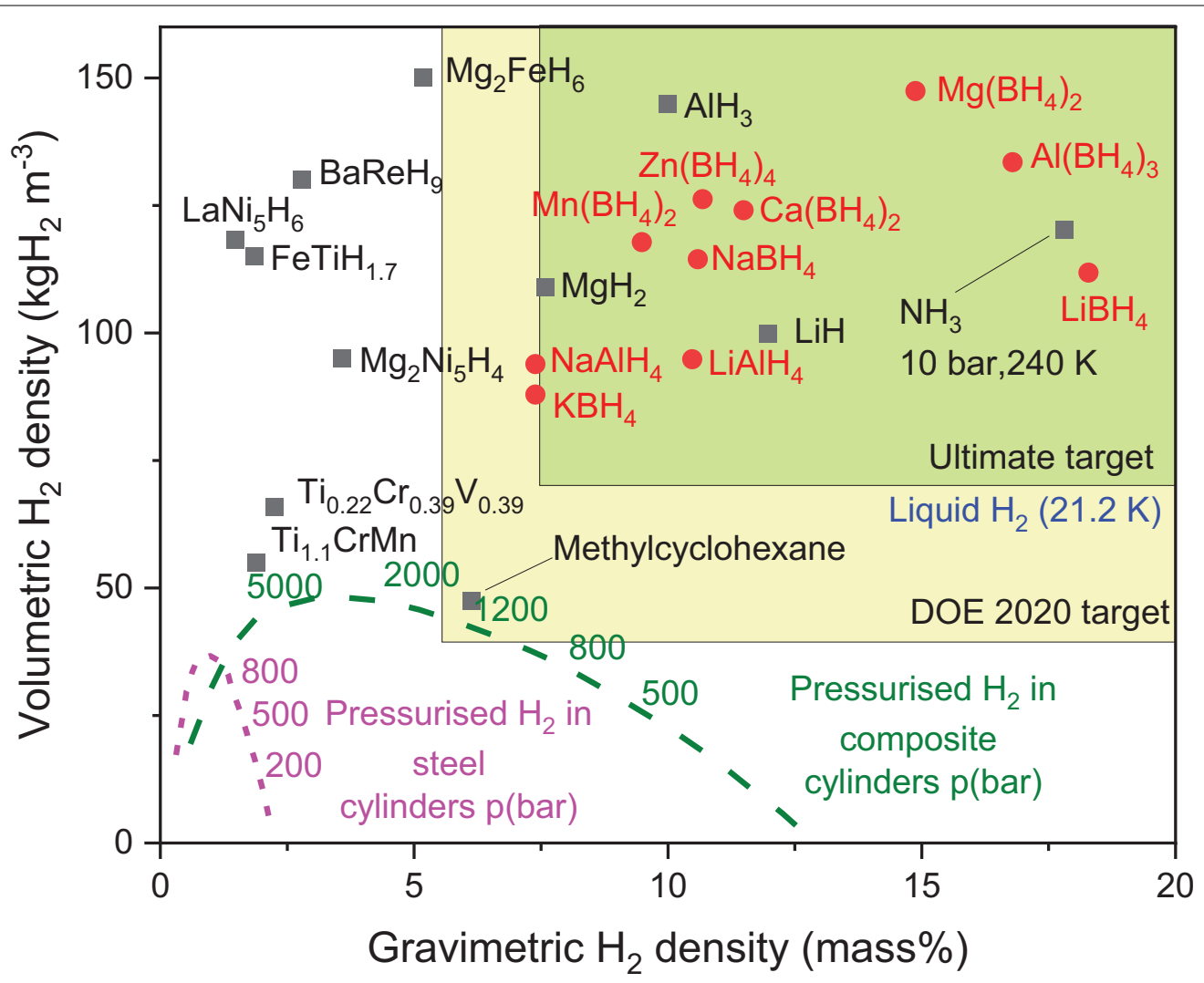

FIGURE 2 | Volumetric and gravimetric hydrogen density of few selected hydrides (Reprinted from Lai and Aguey-Zinsou (2018) and Valera-Medina et al. (2018)). 
requirements but are limited by their irreversible nature (Lai and Aguey-Zinsou, 2018). The alternative option is in using RT intermetallic hydrides such as $\mathrm{TiFeH}_{1.7}$ and $\mathrm{LaNi}_{5} \mathrm{H}_{6}$ that have volumetric densities at par with complex hydrides. Such intermetallic hydrides can be expressed as $\mathrm{A}_{x} \mathrm{~B}_{y} \mathrm{H}_{n}$ where " $\mathrm{A}$ " is typically a rare-earth, alkaline earth metals or a transition metal that can easily form stable hydrides, and " $\mathrm{B}$ " is a transition metal such as $\mathrm{Ni}, \mathrm{Co}, \mathrm{Mn}, \mathrm{Cr}$, etc. which forms unstable hydrides (Broom, 2011). Their low gravimetric capacities, however, may pose challenges in structural support and handling of vessels containing the storage material. This design issue has been dealt with in past stationary systems where $\mathrm{MH}$ was used to feed hydrogen to fuel-cell systems (Table 3; Lototskyy et al., 2017).

This review explores the potential of using RT, $\mathrm{MH}$ for stationary applications. The types of RT, $\mathrm{MH}$, their current synthesis approaches and their design challenges are reviewed below.

\section{BASIC PRINCIPLES OF HYDROGEN STORAGE IN MATERIALS}

Various metals (M) in the periodic table are capable of storing hydrogen in the form of hydrides through the direct dissociative chemisorption of $\mathrm{H}_{2}$ gas following (1) (Figure 4B). This is particularly the case for electropositive elements such as scandium, yttrium, lanthanides, actinides and group 4 and 5 elements (Sandrock, 1999; Züttel, 2003).

$$
\mathrm{M}+\frac{\mathrm{x}}{2} \mathrm{H}_{2} \leftrightarrow \mathrm{MH}_{\mathrm{x}}+\triangle \mathrm{H}^{\theta}
$$

where, $\mathrm{M}$ is the metal or alloy, $x$ is the hydrogen concentration and $\Delta \mathrm{H}^{\theta}$ is the enthalpy of formation of hydride.

However, individual elements are usually not suitable as practical hydrogen storage materials because of their

TABLE 3 | Examples of integration of MH in fuel-cell systems (Buchner and Povel, 1982; Miller and Barnes, 2002; Garrier et al., 2011; Hwang and Chang, 2012; Corgnale et al., 2013; Delhomme et al., 2013; Rizzi et al., 2015; Lototskyy et al., 2017).

\begin{tabular}{|c|c|c|c|c|}
\hline $\begin{array}{l}\text { Fuel cell } \\
\text { Power (kWe) }\end{array}$ & $\begin{array}{l}\text { Metal hydride } \\
\text { (MH) material }\end{array}$ & $\begin{array}{l}\text { Weight MH } \\
\text { (kg) }\end{array}$ & $\begin{array}{c}\mathrm{H}_{2} \text { stored } \\
(\mathrm{kg})\end{array}$ & References \\
\hline 55 & TiFe & 280 & 5 & $\begin{array}{l}\text { Buchner and } \\
\text { Povel, } 1982\end{array}$ \\
\hline 14 & $\begin{array}{c}A B_{2}(A=\mathrm{Ti}+\mathrm{Zr} ; \\
B=\mathrm{Mn}+\mathrm{Fe}+\ldots) \\
\text { (Hydralloy C15/Gfe) }\end{array}$ & 213 & 2.98 & $\begin{array}{c}\text { Miller and } \\
\text { Barnes, } 2002\end{array}$ \\
\hline 6 & $\mathrm{LaNi}_{5}$ & 4.4 & 0.046 & $\begin{array}{l}\text { Hwang and } \\
\text { Chang, } 2012\end{array}$ \\
\hline 1 & $\mathrm{LaNi}_{4.8} \mathrm{Al}_{0.2}$ & $6 \times 4.83$ & 0.279 & $\begin{array}{l}\text { Rizzi et al., } \\
2015\end{array}$ \\
\hline 5 & $\mathrm{MmNi}_{5}$ & 185 & 2 & $\begin{array}{c}\text { Corgnale et al., } \\
2013\end{array}$ \\
\hline 1 & $\mathrm{MgH}_{2}$ & 1.8 & 0.107 & $\begin{array}{l}\text { Garrier et al., } \\
2011 ; \\
\text { Delhomme } \\
\text { et al., } 2013\end{array}$ \\
\hline
\end{tabular}

poor hydrogen storage capacity or the need of high temperatures/pressures for the uptake/release of $\mathrm{H}_{2}$. For example, $\mathrm{TiH}_{2}$ requires temperatures up to $800^{\circ} \mathrm{C}$ to fully release hydrogen (Suwarno et al., 2012).

For stationary applications, hydrogen should be reversibly stored at ambient conditions in materials with minimum energy loss. To reach suitable hydrogen storage properties, several strategies have been explored to modify hydrides of high hydrogen capacity (Lai and Aguey-Zinsou, 2018; Lai et al., 2018). In particular, alloying methods have resulted in various hydrides with hydrogen uptake/release near or at ambient conditions as summarized along the "family tree" on Figure 3. Among these various types of alloys, for the purpose of meeting the specific requirements of stationary applications, intermetallic compounds and solid solution alloys may be of prime interest because of their ability in many cases to operate close to ambient conditions and at relatively low pressures (Sandrock, 1999; Broom, 2011).

\section{Thermodynamics Consideration For Hydrogen Storage at Ambient Conditions}

Hydrogen bonding with hydride forming materials mainly depends on the enthalpy $\left(\Delta \mathrm{H}^{\theta}\right)$ of formation of hydride alloys and the associated entropy $\left(\Delta S^{\theta}\right)$ that can be calculated theoretically using the Miedema's model which is an atomic cell model based on semi-empirical calculations (Miedema et al., 1977; Zhang et al., 2016). $\Delta \mathrm{H}^{\theta}$ determines the general operating temperature and pressure of the hydrogen storage material. While, $\Delta S^{\theta}$ is mainly governed by the entropy of hydrogen gas that is lost during hydrogenation, and thus for metallic hydrides this value is $\sim 130 \mathrm{~J} \mathrm{~mol}^{-1} \mathrm{~K}^{-1} \mathrm{H}_{2}$ (Broom, 2011). For RT uptake and release of hydrogen from materials/metals a desirable hydrogen bond strength is in the range of -10 to $-60 \mathrm{~kJ}$ $\mathrm{mol}^{-1} \mathrm{H}_{2}$ (Sandrock, 1999; Bérubé et al., 2007). To achieve this bond strength, elements with high and low enthalpy values are mixed together to form an alloy. In the case of $\mathrm{LaNi}_{5}$, where La forms $\mathrm{LaH}_{2}$ with $\Delta \mathrm{H}^{\theta}=-280 \mathrm{~kJ} \mathrm{~mol}^{-1} \mathrm{H}_{2}$ (Griessen and Riesterer, 1988; Liu et al., 2017) and Ni forms an unstable hydride with $\Delta \mathrm{H}^{\theta}=-6 \mathrm{~kJ} \mathrm{~mol}^{-1} \mathrm{H}_{2}$ (Griessen and Riesterer, 1988), alloying leads to an $\mathrm{LaNi}_{5}$ intermetallic hydride that has $\Delta \mathrm{H}^{\theta}$ $=-30.8 \mathrm{~kJ} \mathrm{~mol}^{-1} \mathrm{H}_{2}$ (Sandrock, 1999). Based on this alloying approach, Table 4 summarizes examples of RT MH with their thermodynamic properties.

Practically, $\Delta \mathrm{H}^{\theta}$ and $\Delta \mathrm{S}^{\theta}$ can be calculated from the PressureComposition Temperature (PCT) curves (Figure 4A-i) at varying temperatures by using the van't Hoff plot (Sandrock, 1999). The slope of van't Hoff plot and its y-axis intercept (Figure 4A-ii) determines $\Delta \mathrm{H}^{\theta}$ and $\Delta \mathrm{S}^{\theta}$, respectively, according to:

$$
\ln \left(\frac{\mathrm{P}_{\mathrm{eq}}}{\mathrm{P}^{\theta}}\right)=\frac{\Delta \mathrm{H}^{\theta}}{\mathrm{RT}}-\frac{\triangle \mathrm{S}^{\theta}}{\mathrm{R}}
$$

where, $P_{\text {eq }}$ is the equilibrium plateau pressure, $R$ is the gas constant and $T$ is the absolute temperature.

The PCT properties of hydrides state the amount of hydrogen stored at a certain temperature and pressure (Sandrock, 1999). Typical examples of commonly known intermetallic compounds 


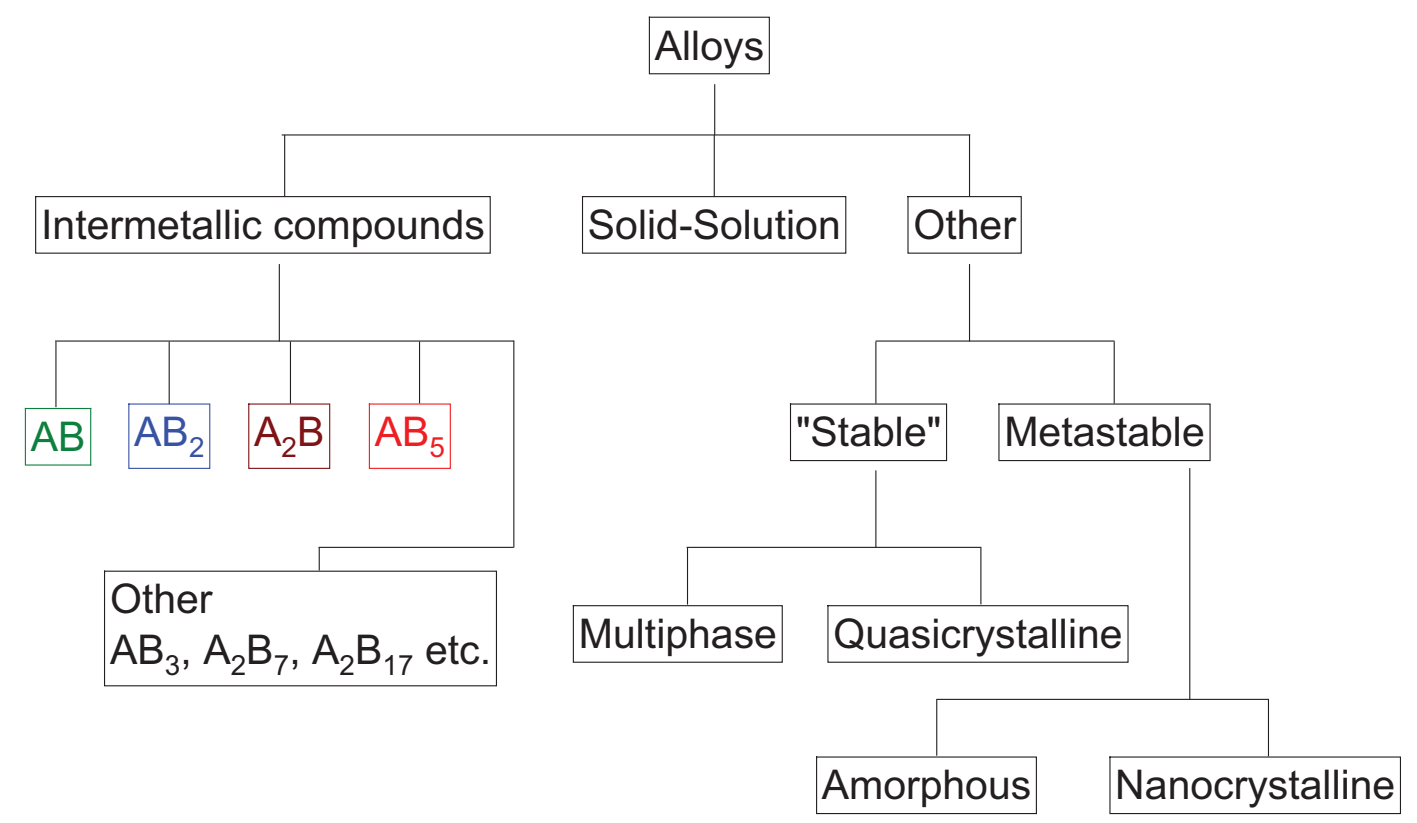

FIGURE 3 | Family tree of metal hydrides (Sandrock, 1999).

are shown in Figure 5 (Sandrock, 1999; Broom, 2011) against the target set in Table 2 for stationary applications. In relation to favorable thermodynamic properties, alloys such as $\mathrm{MmNi}_{5}$, TiFe, $\mathrm{LaNi}_{5}, \mathrm{TiMn}_{1.5}$ and alloys of similar composition are of interest for stationary applications. However, many of these alloys have intrinsic limitations that hinder practical application. For example, the disproportionation of $\mathrm{LaNi}_{5}$ and $\mathrm{MmNi}_{5}$ upon successive hydrogen cycles is a major issue because it results in a reduction of the hydrogen storage capacity upon cycling. Similarly, TiFe suffers from activation issues and thus

TABLE 4 | Enthalpy and entropy values of RT metal hydrides [obtained from ref (Sandrock, 1999) except for the ones cited in the table].

\begin{tabular}{|c|c|c|c|}
\hline Family type & Metal hydrides & $\begin{array}{l}-\Delta \mathbf{H}^{\theta}(\mathbf{k J} \\
\left.\mathrm{mol}^{-1} \mathrm{H}_{2}\right)\end{array}$ & $\begin{array}{c}-\Delta \mathrm{S}^{\theta}(\mathrm{J} \\
\left.\mathrm{K}^{-1} \mathrm{~mol}^{-1}\right)\end{array}$ \\
\hline \multirow[t]{3}{*}{$A B$} & TiFe & 28.1 & 106 \\
\hline & $\mathrm{TiFe}_{0.85} \mathrm{Mn}_{0.15}$ & 29.5 & 107 \\
\hline & $\mathrm{TiFe}_{0.8} \mathrm{Ni}_{0.2}$ & 41.2 & 119 \\
\hline \multirow[t]{4}{*}{$A B_{2}$} & $\mathrm{TiMn}_{1.5}$ & 28.7 & 114 \\
\hline & $\mathrm{ZrFe}_{1.5} \mathrm{Cr}_{0.5}$ & 25.6 & 97 \\
\hline & $\mathrm{Ti}_{0.98} \mathrm{Zr}_{0.02} \mathrm{~V}_{0.43} \mathrm{Fe}_{0.09} \mathrm{Cr}_{0.05} \mathrm{Mn}_{1.5}$ & 27.4 & 112 \\
\hline & $\mathrm{Ti}_{1.1} \mathrm{CrMn}$ (Kojima et al., 2006) & 22.0 & 94 \\
\hline \multirow[t]{4}{*}{$A B_{5}$} & $\mathrm{MmNi}_{5}$ & 21.1 & 97 \\
\hline & $\mathrm{LaNi}_{5}$ & 30.8 & 108 \\
\hline & $\mathrm{LaNi}_{4.25} \mathrm{Al}_{0.75}$ & 44.1 & 117 \\
\hline & $\mathrm{CaNi}_{5}$ & 31.9 & 101 \\
\hline \multirow[t]{3}{*}{ Solid-solution } & $\mathrm{V}_{0.855} \mathrm{Ti}_{0.095} \mathrm{Fe}_{0.05}$ & 43.2 & 140 \\
\hline & $V_{92.5} Z_{7.5}$ (Lototsky et al., 2005) & 40.3 & 147 \\
\hline & $\begin{array}{c}\left(\mathrm{Ti}_{0.16} \mathrm{Zr}_{0.05} \mathrm{Cr}_{0.22} \mathrm{~V}_{0.57}\right)_{0.95} \mathrm{Fe}_{0.05} \\
\text { (Kao et al., 2010) }\end{array}$ & 34.8 & \\
\hline
\end{tabular}

the need of high temperatures and pressures to achieve a first hydrogen uptake. TiFe is also extremely sensitive to impurities and thus easily deactivates upon oxidation. Such a deactivation upon oxidation is also prevalent in $\mathrm{TiMn}_{1.5}$. The latter is also highly pyrophoric.

Hydrogen absorption in metals can follow different paths along the structural formation of various hydride phases. These include the (Sahlberg et al., 2016):

(i) BCC-route where $\mathrm{H} / \mathrm{M}=2: \mathrm{BCC} \rightarrow$ distorted $\mathrm{BCC}(\mathrm{BCT})$ $\rightarrow$ FCC

(ii) $\mathrm{RE}$-route (where $\mathrm{RE}=\mathrm{La}, \mathrm{Ce}, \mathrm{Pr}$, and $\mathrm{Nd}$ ) with $\mathrm{H} / \mathrm{M}>2$ : $d \mathrm{HCP} \rightarrow \mathrm{FCC} \rightarrow$ distorted $\mathrm{FCC}(\mathrm{BCT})$

(iii) High-entropy route with $\mathrm{H} / \mathrm{M}>2.5: \mathrm{BCC} \rightarrow$ distorted $\mathrm{FCC}$ (BCT)

where $\mathrm{H} / \mathrm{M}$ is hydrogen-to-metal atomic ratio

Transition metals such as $\mathrm{Ti}$ and $\mathrm{V}$ that have Body centered Cubic (BCC) structure have been reported to follow the BCCroute with $\mathrm{H} / \mathrm{M}=2$ after full hydrogenation (Sahlberg et al., 2016; Lai et al., 2018). Along this route, a phase transformation is observed from the initial BCC structure to a distorted BCC (i.e., a Body centered Tetragonal phase, BCT) upon the formation of the hydride phase, and finally a Face-centered cubic (FCC) structure upon full hydrogenation, i.e., formation of $\mathrm{TiH}_{2}$ and $\mathrm{VH}_{2}$ (Sahlberg et al., 2016). Comparatively, rare-earth metals such as $\mathrm{La}, \mathrm{Ce}, \mathrm{Pr}$, and $\mathrm{Nd}$ follows the Rare-Earth route (REroute). Initially, these metals $(\mathrm{H} / \mathrm{M}=0)$ with a double Hexagonal Closed Packed ( $d \mathrm{HCP})$ structure directly forms an intermediate FCC structure (at $\mathrm{H} / \mathrm{M}<\sim 2.3$ ). Upon further hydrogenation and with $\mathrm{H} / \mathrm{M}>2.3$, a tetragonal distortion is observed leading to distorted FCC (BCT) hydride phase (Sahlberg et al., 2016). Although higher $\mathrm{H} / \mathrm{M}$ ratios are observed along the RE-route 


\section{A (i) PCT curve}

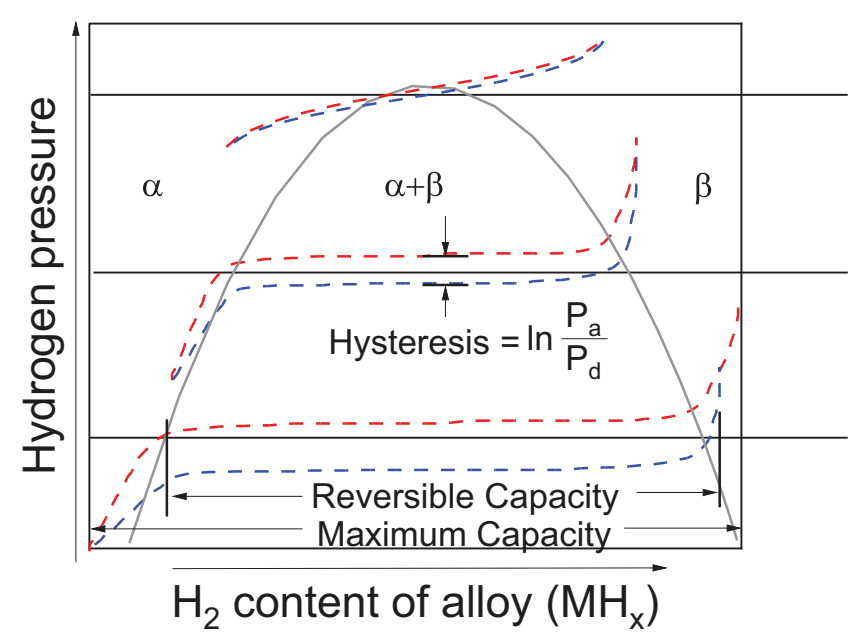

(ii) Van't Hoff plot

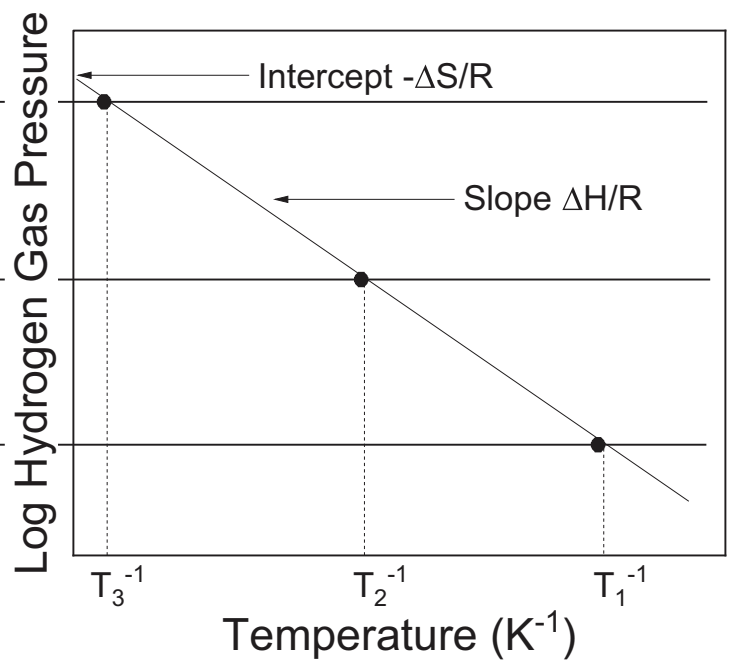

B

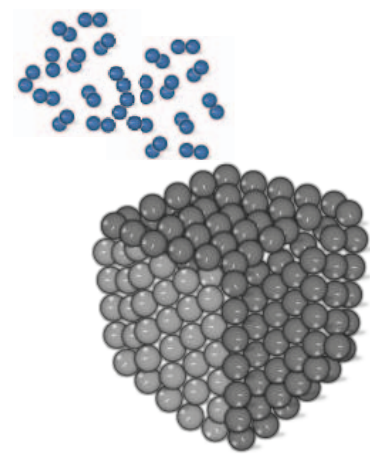

$\alpha$

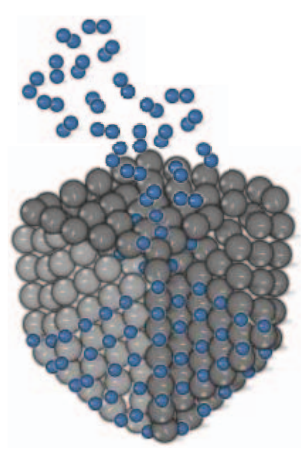

$\alpha+\beta$

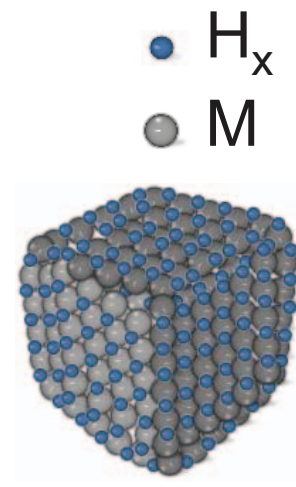

$\beta$

$\mathrm{H}_{2}$ desorbed

$\mathrm{H}_{2}$ absorbed

FIGURE 4 | (A) (i) Pressure-composition-temperature (PCT) curve, (ii) Van't Hoff plot of a typical metal hydride based hydrogen storage (Klebanoff, 2012);

(B) Physical representation of transition between phases as hydrogen is being absorbed or desorbed where $\alpha$ and $\boldsymbol{\beta}$ correspond to the metal and metal hydride phase, respectively.

compared to BCC-route, the weight penalty of the rare-earth elements, e.g., $\mathrm{La}\left(138 \mathrm{~g} \mathrm{~mol}^{-1}\right)$, as compared to $\mathrm{Ti}(47 \mathrm{~g}$ $\mathrm{mol}^{-1}$ ) leads to low gravimetric hydrogen storage capacities. This indicates a tradeoff when considering the BCC and RE-route to develop hydrogen storage materials. An alternative has been explored through the approach of the high-entropy route where a combination of transition metals is used to reach $\mathrm{H} / \mathrm{M}>2.3$ with a distorted FCC structure. Such high-entropy based alloys are expected to display superior hydrogen properties as compared to conventional alloys while avoiding the use of rare-earth elements i.e., (i) a high storage capacity with a H/M ratio of 2.5 and (ii) a high lattice distortion leading to additional lattice strain favorable for hydride formation (Sahlberg et al., 2016). High entropy alloys tend to be based on at least five metallic elements in an equimolar ratio or with varying composition from 5 to $35 \%$; where the entropy of mixing is larger than $1.61 \mathrm{R}$ (where $R$ is gas constant $) \approx 13.4 \mathrm{~J} \cdot \mathrm{mol}^{-1} \mathrm{~K}^{-1}$. In comparison, conventional alloys have an entropy of mixing lower than 0.69R (Zhang and Zhou, 2007). Preliminary investigations have been reported on high entropy alloys including CoFeMn-TiVZr (Kao et al., 2010), ZrTiVCrFeNi (Kunce et al., 2013), and $\mathrm{MgZrTiFe}_{0.5} \mathrm{Co}_{0.5} \mathrm{Ni}_{0.5}$ (Zepon et al., 2018). In the case of CoFeMn-TiVZr, Kao et al. (2010) demonstrated a hydrogen storage capacity of $1.8 \mathrm{wt} \%$ $\mathrm{H}_{2}$ at $25^{\circ} \mathrm{C}$. This equates to a $\mathrm{H} / \mathrm{M}$ ratio of $\sim 1$ as compared 


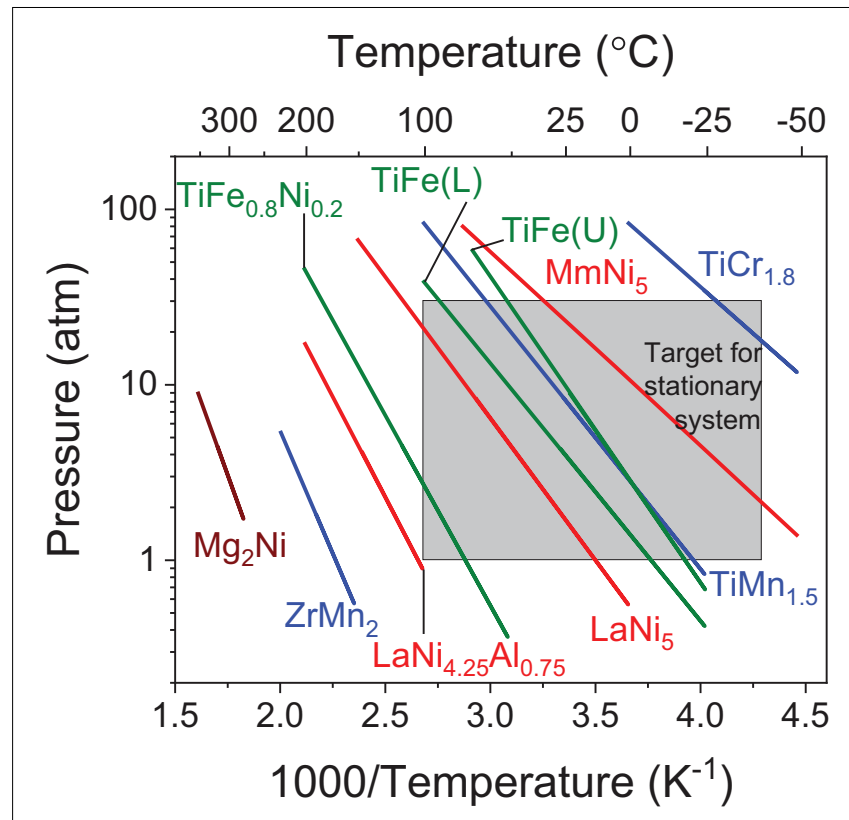

FIGURE 5 | Van't Hoff plots showing examples of decomposition plateau of common intermetallic hydrides with the estimated targets for stationary application (shown in Table 2); [color scheme: $A B$ (green), $A B_{2}$ (blue), $A_{2} B$ (brown), and $A B_{5}$ (red)]; (L) indicates lower plateau, (U) indicates upper plateau and Mm represents Mischmetal (Sandrock, 1999; Broom, 2011).

to the expected >2.5. Similarly, $1.8 \mathrm{wt} \% \mathrm{H}_{2}$ at $50^{\circ} \mathrm{C}$ was observed for $\mathrm{Zr}_{0.163} \mathrm{Ti}_{0.162} \mathrm{~V}_{0.222} \mathrm{Cr}_{0.135} \mathrm{Fe}_{0.158} \mathrm{Ni}_{0.160}$ and this again corresponds to a $\mathrm{H} / \mathrm{M}$ ratio of $\sim 1$. Zepon et al. (2018) used a high temperature hydride $\mathrm{MgZrTiFe}_{0.5} \mathrm{Co}_{0.5} \mathrm{Ni}_{0.5}$ (1.2 wt\% $\mathrm{H}_{2}$ at $350^{\circ} \mathrm{C}$ ) to confirm the difficulty of forming the right structural phases, and in this case an incomplete transformation of the BCC phase into FCC upon hydrogenation. Comparatively, TiVZrNbHf displayed a $\mathrm{H} / \mathrm{M}$ ratio of 2.5 at $300^{\circ} \mathrm{C}$ which is equivalent to $2.7 \mathrm{wt} \% \mathrm{H}_{2}$ (Sahlberg et al., 2016). TiVZrNbHf was reported to have both tetrahedral sites and $\sim 50 \%$ of octahedral sites filled with hydrogen (Sahlberg et al., 2016). This behavior is unique compared to binary hydrides such as $\mathrm{TiH}_{2}$ and $\mathrm{VH}_{2}$ that stores hydrogen only at tetrahedral interstitial sites (Quijano et al., 2009). Due to the high entropy alloys being recently introduced, further investigations need to be carried out on its synthesis to achieve $\mathrm{H} / \mathrm{M}>2.5$. For example, TiVZrNbHf that achieved $\mathrm{H} / \mathrm{M}>2.5$ and CoFeMn-TiVZr that reported $\mathrm{H} / \mathrm{M} \sim 1$ both were synthesized by arc-melting process suggesting further investigation on the synthesis process to achieve higher $\mathrm{H} / \mathrm{M}$ (Kao et al., 2010; Sahlberg et al., 2016).

\section{Kinetics Consideration for Hydrogen Storage at Ambient Conditions}

For stationary applications, the kinetics of RT hydrides are expected to be fast, i.e., $<3 \mathrm{~min}$ for full hydrogen uptake/release in order to provide fast response times in conjunction with the fuel cell. This means that at the material level the hydrogen absorption/desorption process should involve low energy barriers. At the macroscopic level, the initial hydrogen pressure and temperature can determine the various limiting rates (Figure 6A; Rudman, 1983; Bloch and Mintz, 1997). However, at a given temperature and pressure, the hydrogen absorption/release rate is dictated by the materials' intrinsic properties. The metal-hydrogen interaction depends upon several factors (Figure 6B) associated with activation barriers including that of the $\mathrm{H}_{2}$ physisorption $\left(E_{\text {phys }}\right)$, chemisorption $\left(E_{\text {chem }}\right)$, penetration $\left(E_{\text {pen }}\right)$, diffusion $\left(E_{\text {diff }}\right)$ and the nucleation and growth ( $\left.E_{\text {nuc/growth }}\right)$ of the hydride phase (Rudman, 1983; Bloch and Mintz, 1997; Lai et al., 2018). The initial physisorption of hydrogen molecules corresponds to their direct adsorption onto the alloy surface through Van der Waals forces $\left(E_{\text {phys }} \approx 10 \mathrm{~kJ}\right.$ $\mathrm{mol}^{-1} \mathrm{H}_{2}$ ) (Züttel, 2003). At the metal surface the energy required $\left(E_{\mathrm{chem}}\right)$ for dissociation and formation of a metalhydrogen bond via chemisorption is $\approx 50 \mathrm{~kJ} \mathrm{~mol}^{-1} \mathrm{H}_{2}$ (Züttel, 2003). The hydrogen atoms then penetrate the subsurface of metal $\left(E_{\text {pen }}\right)$ and populate the interstitial sites of the material through surface diffusion $\left(E_{\text {diff }}\right)$. Higher concentration of hydrogen atoms leads to the formation of stable metallic hydride phase ( $\left.E_{\text {nuc/growth }}\right)$.

The overall rate limiting step of hydrogen sorption can be determined from the reaction rate coefficient $k(\mathrm{~T})$, arising from the Arrhenius equation (Sun et al., 2018):

$$
k(T)=A e^{\frac{-E_{a}}{R T}}
$$

where, $k(T)$ is the rate constant, $\mathrm{E}_{\mathrm{a}}$ is the activation energy and a is the pre-exponential factor.

Out of the five energy barriers stated above, one energy barrier will be much higher than others and that would determine the rate determing step while other reaction steps would perform in equilibrium (Martin et al., 1996). For $\mathrm{LaNi}_{4.7} \mathrm{Al}_{0.3}$, for example, the hydrogenation barrier is associated with the surface reactivity $\left(E_{\text {chem }}\right)$ while the desorption process is controlled by the $\mathrm{H}_{2}$ diffusion barrier ( $\left.E_{\text {diff }}\right)$ (Martin et al., 1996). Studies on materials like $\mathrm{Mg}_{2} \mathrm{Ni}, \mathrm{LaNi}_{5}$, and TiFe have also shown similar behaviors where the dissociation process at the surface affects the absorption kinetics of the alloy (Zaluski et al., 1995a). Using catalysts like $\mathrm{Pd}, \mathrm{Ni}$, or $\mathrm{Fe}$ aids the dissociation of $\mathrm{H}_{2}$ to enhance hydrogen absorption (Uchida et al., 1991). Therefore, surface segregation of metallic Ni in $\mathrm{LaNi}_{5}$ and $\mathrm{Mg}_{2} \mathrm{Ni}$ and $\mathrm{Fe}$ in TiFe were proposed as the prime mechanism for the initial activation of these alloys (Broom, 2011). Before activation, TiFe is more difficult to activate than $A B_{5}$ type alloys, and despite extensive investigations, the exact mechanism and the general rules controlling the initial activation of TiFe are still unclear (Edalati et al., 2018). Many mechanisms based on surface activation have been proposed to explain the poor activation of TiFe. This includes: (a) surface segregation of catalytically active $\mathrm{Fe}$ (Schlapbach et al., 1980), (b) dissolution of the surface oxide in the bulk (Schober and Westlake, 1981), and (c) poor hydrogen transport through the oxide layer (Jai-Young et al., 1983). Defects at the surface of the alloy and dissolution of the surface oxide layer are other possible approaches that have been proposed to enhance the permeability of hydrogen in the surface oxide layer (Broom, 2011; Edalati et al., 2018). Upon $\mathrm{H}_{2}$ sorption, 


\section{A External kinetic parameters: (i) $\mathrm{H}_{2}$ flow rate (ii) Temperature}

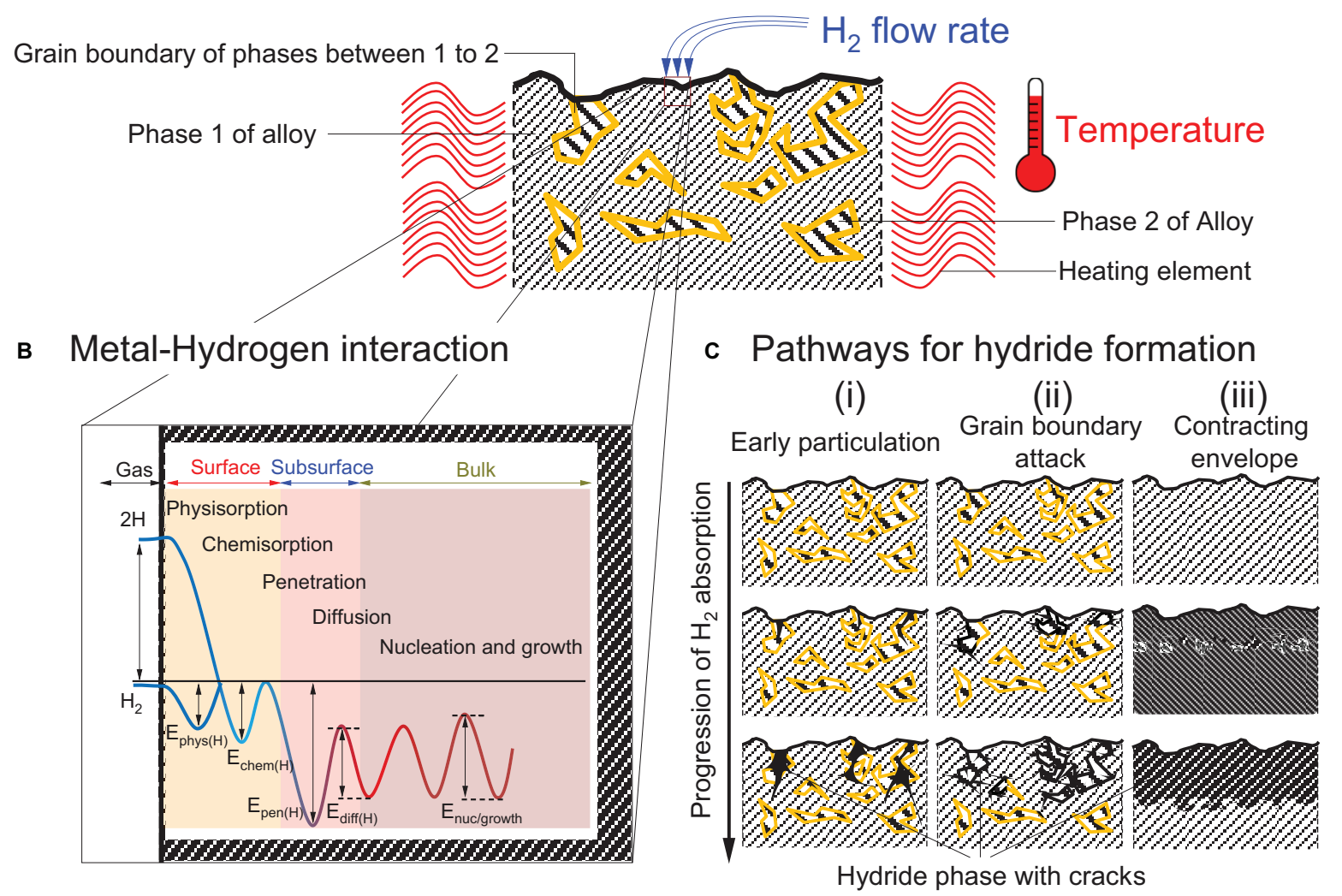

FIGURE 6 | Schematic illustrations of the factors that affect the limiting rate of reaction (A) Cross-section of the alloy that has two phases: phase 1 (color: gray) and phase 2 (color: yellow) before hydrogenation and being exposed to (i) $\mathrm{H}_{2}$ gas and (ii) temperature variation. (Lee and Perng, 1991; Bloch and Mintz, 1997); (B) One-dimensional Lennard Jones potential curve of the reaction exposing the material to $\mathrm{H}_{2}$ gas with postulated energy barriers for the hydrogenation of metal. (E represents an energy with subscript: phys $(\mathrm{H})$, chem $(\mathrm{H})$, pen $(\mathrm{H})$, diff( $(\mathrm{H})$, and nuc/growth as $\mathrm{H}_{2}$ physisorption, chemisorption, penetration in the subsurface, diffusion in bulk, and nucleation and growth of hydride phase, respectively.) (Lai et al., 2015), (C) Topochemical progression of metal hydrides (color: black) showing different pathways for hydride penetration: (i) Early particulation, (ii) Grain boundary attack, and (iii) Contracting envelope showing the progression of metal hydrides with cracks through phase 2, the grain boundary region between phase 1 and 2 and diffusing uniformly from metal surface, respectively (Mintz and Bloch, 1985; Lee and Perng, 1991; Bloch and Mintz, 1997).

several macroscopic growth regimes of the hydride phase have also been reported (Figure 6C). These includes the: (i) early particulation, (ii) grain boundary attack, and (iii) contracting envelope mechanisms. Under the contracting envelope concept, the metal hydride nuclei form a continuous layer on the surface of the alloy particles (Mintz and Bloch, 1985; Bloch and Mintz, 1997). In contrast, upon early particulation the hydride phase nucleates in an heterogeneous manner across the alloy's surface and bulk. Such a mechanism is more prevalent in brittle intermetallics and has been observed with $\mathrm{Ti}_{1+x} \mathrm{Fe}$ alloys, for example (Lee and Perng, 1991). In the concept of grain boundary attack, the nucleation of the hydride phase is expected to occur at defected sites and grain boundaries (Bloch and Mintz, 1997). For example, in $\mathrm{Zr}$ above the eutectoid temperature $\left(550^{\circ} \mathrm{C}\right)$, the formation of the initial hydride phase has been reported to exclusively occur at grain boundaries (Bloch, 1995). This particular phenomenon has also been reported in certain rare-earth metals such as $\mathrm{Tb}$,
Dy, Ho, and Er at high temperatures (Bloch et al., 1984; Bloch and Mintz, 1997).

Although it has been suggested that the early particulation mechanism (Figure 6C-i) for Ti-based materials is related to surface activation, many studies have also reported a grain boundary attack mechanism (Figure 6C-ii) as the main path for hydrogen sorption (Miraglia et al., 2012; Lv and Huot, 2017). In particular upon the addition of second-phases such as $\mathrm{Zr}_{7} \mathrm{Ni}_{10}$ in $\mathrm{Ti}_{1-x} \mathrm{~V}_{1-y} \mathrm{Cr}_{1+x+y}(\mathrm{x} \leq 0.4, \mathrm{y} \leq 0.3)$ (Miraglia et al., 2012) and $\mathrm{ZrMn}_{2}$ in TiFe (Lv and Huot, 2017). To promote a grain boundary attack mechanism for hydrogen absorption, using mechanical treatment has also been reported to be effective (Hongo et al., 2015). For example, Edalati et al. $(2013,2014)$ have shown that through the application of high-pressure torsion to $\mathrm{Mg}_{2} \mathrm{Ni}$ (Hongo et al., 2015), TiFe, $\mathrm{TiFe}_{1-x} \mathrm{Mn}_{x}$ where $(x=0,0.15$ and 0.3 ) (Edalati et al., 2016a) and Ti-V alloys (Edalati et al., 2016b) the initial hydrogen activation was facilitated. 


\section{CURRENT ROOM TEMPERATURE HYDRIDES AND THEIR HYDROGEN PROPERTIES}

Among the many RT hydrides reported to date, intermetallics and solid-solution alloys are currently the most promising for stationary applications owing to the ability of many of these alloys to store hydrogen at ambient conditions (Table 5; Rusman and Dahari, 2016; Hirscher et al., 2020).
These include TiFe, $\mathrm{TiMn}_{2}$-based, $\mathrm{LaNi}_{5}$ and $\mathrm{Ti}-\mathrm{V}-\mathrm{Cr}$ as their parent alloys.

\section{AB Alloys}

TiFe is a low-cost well-known hydrogen storage material of the AB-type family. It releases hydrogen under ambient conditions and has a $1.9 \mathrm{wt} \% \mathrm{H}_{2}$ storage capacity (Bououdina et al., 2006). However, this alloy suffers from drawbacks with respect to hydrogen activation, i.e., the freshly prepared alloy does

TABLE 5 | Examples of Metal Hydrides and their properties (Sakintuna et al., 2007).

\begin{tabular}{|c|c|c|c|c|}
\hline Type & Material & $\begin{array}{l}\text { Hydrogen storage } \\
\text { properties } \\
\left.\text { (mass } \% / \mathrm{min} /{ }^{\circ} \mathrm{C} / \mathrm{MPa}\right)\end{array}$ & Other properties & References \\
\hline \multirow[t]{3}{*}{$A B$} & TiFe $+x$ wt $\% Y(x=4,6$, and 8$)$ & - Abs: 1.2/3/25/- & $\begin{array}{l}\text { - Y with } 8 \text { wt\% improved first hydrogenation } \\
\text { kinetics }\end{array}$ & $\begin{array}{l}\text { Gosselin and Huot, } \\
2019\end{array}$ \\
\hline & $\mathrm{Ti}_{1-x} \mathrm{FeZr}_{x}(x=0.1,0.2$ and 0.5$)$ & - Des: 1.29/-/20/- & - Zr lowers $P_{e q}$ and narrows width of plateau & $\begin{array}{l}\text { Nishimiya et al., } \\
2000\end{array}$ \\
\hline & FeTi & - Abs: 1.92/-/25/10 & - Relaxation effects were studied by ball-milling & $\begin{array}{l}\text { Zaluski et al., } \\
1995 b\end{array}$ \\
\hline \multirow[t]{5}{*}{$A B_{2}$} & $\begin{array}{c}\mathrm{Ti}_{1-x} \mathrm{Zr}_{x} \mathrm{Cr}_{y 1} \mathrm{Mn}_{y 2} \mathrm{Ni}_{y_{3}} \mathrm{Fe}_{y 4} \mathrm{~V}_{y 5} \\
(x=0.05-0.45, y 1=0.1-0.4 \\
y 2=0.3-1.2, y 3=0.2-0.3 \\
y 4=0.05-0.5, y 5=0-0.6)\end{array}$ & - Abs: 1.5/-/20/-Des: 1.5/-/20/- & $\begin{array}{l}\text { - Tuning of the } \mathrm{H}_{2} \text { storage properties can be } \\
\text { easily achieved by variations in content of } \mathrm{Zr}, \mathrm{V} \\
\text { and } \mathrm{Cr}\end{array}$ & $\begin{array}{l}\text { Pickering et al., } \\
2018\end{array}$ \\
\hline & $\mathrm{Zr}_{0.75} \mathrm{Ti}_{0.25} \mathrm{Cr}_{1.5} \mathrm{Ni}_{0.5}$ & $\begin{array}{l}\text { - Abs: 1.75/-/40/4.7 Des: } \\
\text { 1.05/-/40/0.006 }\end{array}$ & $\begin{array}{l}\text { - Linear relationship between lattice parameters } \\
\text { and ( } \mathrm{Ti} \text { and } \mathrm{Ni}) \text { parameters giving single phase } \\
\text { with steep plateau slope }\end{array}$ & $\begin{array}{l}\text { Bououdina et al., } \\
1998\end{array}$ \\
\hline & $\mathrm{Ti}_{1.1} \mathrm{CrMn}$ & $\begin{array}{l}\text { - Abs: 1.80/1/23/33 Des: } \\
\text { 1.75/5/23/0.1 }\end{array}$ & $\begin{array}{l}-\Delta \mathrm{H}=-22 \mathrm{~kJ} \mathrm{~mol}^{-1} \mathrm{H}_{2}\left(10 \mathrm{~kJ} \mathrm{~mol}^{-1} \mathrm{H}_{2}\right. \\
\left.\text { absolute value smaller than } \mathrm{LaNi}_{5} \text { and Ti-V-Cr }\right)\end{array}$ & Kojima et al., 2006 \\
\hline & & & $\begin{array}{l}\text { - Kinetics of the alloy was similar to } \\
\text { compressed hydrogen }\end{array}$ & \\
\hline & $\mathrm{TiCr}_{1.1} \mathrm{~V}_{0.9}$ & $\begin{array}{l}\text { - Abs: 3.5/-/30/1.7 Des: } \\
\text { 2.5/-/30/0.05 }\end{array}$ & $\begin{array}{l}\text { - Maximum hydrogen capacity is reduced after } \\
\text { melting/mechanical alloying with } \mathrm{LaNi}_{5} \text { addition }\end{array}$ & $\begin{array}{l}\text { dos Santos et al., } \\
2003\end{array}$ \\
\hline \multirow[t]{4}{*}{$A B_{5}$} & $\mathrm{LaNi}_{5}$ & $\begin{array}{l}\text { - Abs: 1.3/-/25/1 Des: } \\
\text { 1.3/-/25/0.02 }\end{array}$ & $\begin{array}{l}\text { - Mechanical milling of La and Ni powder can } \\
\text { result directly into nanocrystalline } A B_{5} \text { phase }\end{array}$ & Liang et al., 2001a \\
\hline & & & $\begin{array}{l}\text { - Annealing at } 550^{\circ} \mathrm{C} \text { for } 3 \mathrm{~h} \text { under vacuum } \\
\text { pressure of }<10^{-2} \mathrm{~Pa} \text { after milling improves } \\
\text { hydrogen storage capacity showing a similar } \\
\text { capacity to the melt casting alloys }\end{array}$ & \\
\hline & $\mathrm{CaNi}_{5}$ & $\begin{array}{l}\text { - Abs: 1.5/-/30/1.5 Des: } \\
\text { 1.2/-/30/0.01 }\end{array}$ & $\begin{array}{l}\text { - Mechanical milling of } \mathrm{Ca} \text { and } \mathrm{Ni} \text { powder does } \\
\text { not form } \mathrm{CaNi}_{5} \text { phase }\end{array}$ & Liang et al., 2001b \\
\hline & & & $\begin{array}{l}\text { - Post-milling annealing at } 640^{\circ} \mathrm{C} \text { for } 2 \mathrm{~h} \text { under } \\
\text { vacuum pressure of }<10^{-2} \mathrm{~Pa} \text { improves the } \\
\text { hydrogen storage capacity }\end{array}$ & \\
\hline \multirow[t]{6}{*}{ Solid-solution } & $\mathrm{VZr}_{x} \mathrm{Ti}_{x} \mathrm{Ni}_{x}(x$ is $7.4 \mathrm{wt} \%$ of $\mathrm{V})$ & $\begin{array}{l}\text { - Abs: 2.0/-/40/1 Des: } \\
\text { 1.6/-/40/0.05 }\end{array}$ & $\begin{array}{l}\text { - Zr improves hydrogen absorption in forming } \\
\text { C14 Laves phase }\end{array}$ & Kuriiwa et al., 1999 \\
\hline & $\mathrm{V}_{0.375} \mathrm{Ti}_{0.25} \mathrm{Cr}_{0.30} \mathrm{Mn}_{0.075}$ & $\begin{array}{l}\text { - Abs: 3.0/-/30/5 Des: } \\
\text { 2.2/-/30/0.002 }\end{array}$ & $\begin{array}{l}\text { - Annealing for } 1 \mathrm{~h} \text { at } 1,300^{\circ} \mathrm{C} \text { gives a uniform } \\
\text { bcc phase solid solution with improvement in } \\
\text { storage capacity }\end{array}$ & Seo et al., 2003 \\
\hline & $\mathrm{Ti}_{40} \mathrm{~V}_{7.5} \mathrm{Cr}_{55}$ & $\begin{array}{l}\text { - Abs: 2.8/-/40/10 Des: } \\
\text { 2.2/-/40/0.01 }\end{array}$ & $\begin{array}{l}\text { - Capacity was improved by using low } \\
\text { vanadium content and annealing treatment over } \\
1400^{\circ} \mathrm{C} \text { for } 1 \text { min to stabilize bcc structure }\end{array}$ & Okada et al., 2002 \\
\hline & $\mathrm{TiCr}_{10} \mathrm{Mn}_{18} \mathrm{~V}_{27} \mathrm{Fe}_{5}$ & $\begin{array}{l}\text { - Abs: 3.01/8/60/3 Des: } \\
\text { 2.0/-/60/0.003 }\end{array}$ & $\begin{array}{l}\text { - Fe addition improves the activation } \\
\text { performance, increases desorption capacity } \\
\text { and reduces hysteresis but decreases } \\
\text { absorption capacity }\end{array}$ & Yu et al., 2006 \\
\hline & $\mathrm{TiCr}_{10} \mathrm{Mn}_{18} \mathrm{~V}_{32}$ & $\begin{array}{l}\text { - Abs: 3.36/8/60/3 Des: } \\
\text { 1.96/-/60/0.003 }\end{array}$ & $\begin{array}{l}\text { - Three forms of hydride formation took place } \\
\text { for the alloy: BCC }\left(1.5 \mathrm{wt} \% \mathrm{H}_{2}\right) \text {, Deformed } \\
\text { FCC }\left(3 \mathrm{wt} \% \mathrm{H}_{2}\right) \text { and FCC(full hydride) }\end{array}$ & Yu et al., 2006 \\
\hline & $\mathrm{TiV}_{32} \mathrm{Cr}_{10} \mathrm{Mn}_{18}$ & $\begin{array}{l}\text { - Abs: 3.98/6/20/3 Des: } \\
\text { 2.4/-/80/0.003 }\end{array}$ & $\begin{array}{l}\text { - Increase of } V \text { content changes two phase } \mathrm{C} 14 \\
\text { Laves phase and BCC phase into a single BCC } \\
\text { phase }\end{array}$ & Yu et al., 2004 \\
\hline
\end{tabular}

\footnotetext{
a Storage capacity (mass\%)/full kinetics time (min)/operating temperature $\left({ }^{\circ} \mathrm{C}\right)$ /equilibrium plateau pressure $(\mathrm{MPa})$.
} 
not absorb hydrogen at ambient conditions. TiFe is extremely sensitivity to oxidation and thus one possible explanation is the formation of a Ti oxide layer at the metal alloy's surface preventing any hydrogen penetration into the alloy (Bououdina et al., 2006). Another drawback limiting the use of TiFe is the large hysteresis between its absorption and desorption equilibrium plateau pressures, $\geq 1$ and $\leq 0.7 \mathrm{MPa}$ at $40^{\circ} \mathrm{C}$, respectively (Reilly and Wiswall, 1974). To solve this, small substitutions with other elements, e.g., $\mathrm{Mn}, \mathrm{Co}, \mathrm{Cr}$, or $\mathrm{Ni}$, have been investigated with the aim of forming a pseudo-binary alloy $\mathrm{TiFe}_{x} \mathrm{M}_{1-x}$, where $0 \leq \times \leq 0.5$; and such an approach effectively results in a reduction of the hysteresis (Mintz et al., 1981).

Many efforts have also focused toward understanding the activation mechanism of TiFe based materials once exposed to hydrogen. To this aim, activation routes such as ball-milling (Emami et al., 2015), high pressure torsion (Edalati et al., 2013), cold rolling (Vega et al., 2018), and Pd doping (Davids et al., 2011) have been investigated. However, all these methods have been found to have a detrimental effect on the hydrogen storage capacity (Reilly and Wiswall, 1974; Suda et al., 2002).
For example, Emami et al. (2015) reported that the $\mathrm{H}_{2}$ storage capacity of TiFe dropped to $1.5 \mathrm{wt} \%$ after ball-milling. Edalati et al. (2013) also reported a reduction of the $\mathrm{H}_{2}$ storage capacity to $\sim 1.7 \mathrm{wt} \%$ upon using high pressure torsion. Similarly, a $1.4 \mathrm{wt} \%$ $\mathrm{H}_{2}$ capacity was observed for cold rolled FeTi (Vega et al., 2018). However, upon comparing the effect of ball-milling and cold rolling on air exposed $\mathrm{TiFe}+4 \% \mathrm{Zr}$, cold-rolling was found to lead to a lesser loss of hydrogen capacity (Manna et al., 2018).

\section{$\mathrm{AB}_{5}$ Alloys}

Another intermetallic that has been extensively investigated is $\mathrm{LaNi}_{5}\left(A B_{5}\right.$ based intermetallic hydride). This hydride readily forms $\mathrm{LaNi}_{5} \mathrm{H}_{6}$ hydride $\left(1.2 \mathrm{wt} \% \mathrm{H}_{2}\right)$ upon exposure to moderate hydrogen pressures at ambient temperature (Sandrock, 1999). The enthalpy of formation and decomposition of the hydride is -15.7 and $-15.1 \mathrm{~kJ} \mathrm{~mol}^{-1} \mathrm{H}$, respectively (Luo et al., 1998). Some of the properties of $\mathrm{LaNi}_{5}$ are summarized in Figure 7. $\mathrm{LaNi}_{5} \mathrm{H}_{6}$ has a hexagonal structure akin to the $\mathrm{CaCu}_{5}$ phase (Joubert et al., $1999,2002)$. In its dehydrided state, $\mathrm{LaNi}_{5}$ has also a hexagonal structure with a space group of P6/mmm (Joubert et al., 1999);
A

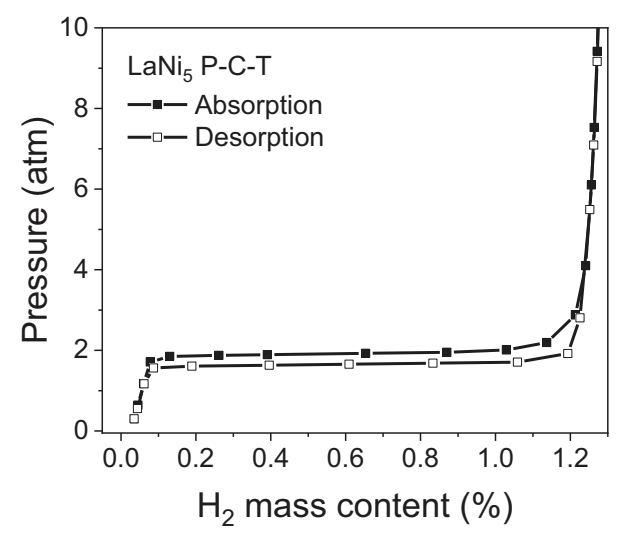

C

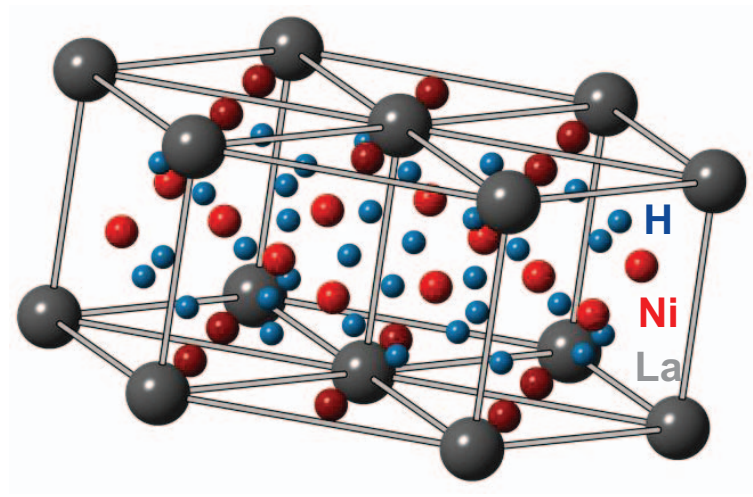

B

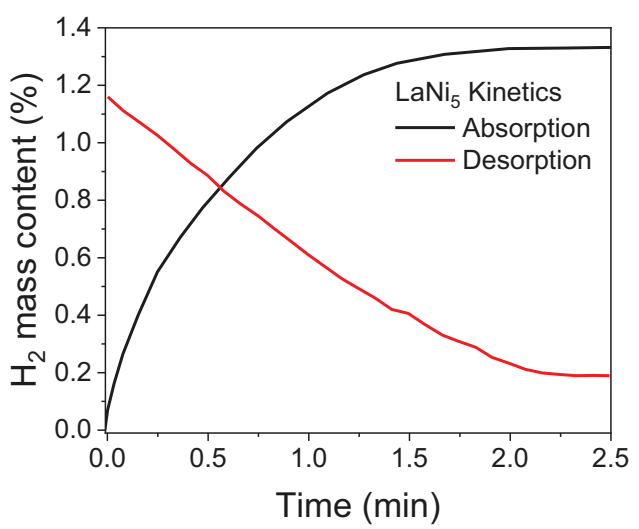

D

\begin{tabular}{lcc}
\hline Physical properties & Units & LaNi $_{5}$ \\
\hline Density $(\rho)$ & $\mathrm{kg} \mathrm{m}^{-3}$ & 8400 \\
Specific heat $\left(\mathrm{C}_{\mathrm{p}}\right)$ & $\mathrm{J} \mathrm{kg}^{-1} \mathrm{~K}^{-1}$ & 419 \\
Effective thermal & $\mathrm{W} \mathrm{m}^{-1} \mathrm{~K}^{-1}$ & 1.0 \\
conductivity $\left(\lambda_{\text {eff }}\right)$ & & \\
Permeability $(\mathrm{K})$ & $\mathrm{m}^{2}$ & $1.0 \times 10^{-12}$ \\
Reaction enthalpy $(\Delta \mathrm{H})$ & $\mathrm{J} \mathrm{mol}^{-1}$ & $3.01 \times 10^{4}$ \\
Porosity $(\varepsilon)$ & & 0.5 \\
\hline
\end{tabular}

FIGURE 7 | LaNi 5 properties: (A) Absorption-desorption PCT curve at $25^{\circ} \mathrm{C}$ (Sandrock, 1997); (B) Kinetics showing typical 1 st cycle of absorption at $25^{\circ} \mathrm{C}$ and $0.34 \mathrm{MPa}$ (Sandrock, 1997) and desorption at $30^{\circ} \mathrm{C}$ and $0.05 \mathrm{MPa}$ (Dhaou et al., 2007); (C) Structural properties showing CaCu5-type hexagonal structure (Liu et al., 2011); (D) Physical properties of LaNis (Yang et al., 2012). 
hence $\mathrm{LaNi}_{5}$ does not undergo any structural changes upon hydrogen absorption/release and this results in less strain induced effects during hydrogen cycling (Sahlberg et al., 2016). Mechanically milling $\mathrm{La}$ and $\mathrm{Ni}$ in a powder form has been shown to lead to the formation of nanocrystalline $\mathrm{LaNi}_{5}$. However, the hydrogen properties of nanocrystalline $\mathrm{LaNi}_{5}$ are relatively poor in terms of hydrogen reversibility and hydrogen capacity $(0.8 \mathrm{wt} \%)$. Having low micro strain $(\sim 0.05 \%)$ and relatively large crystalline grain ( $>28 \pm 2 \mathrm{~nm}$ ) has been found to be preferable (Liang et al., 2001a). $\mathrm{LaNi}_{5}$ is relativity resistant to oxidation, i.e., upon oxidation the activation of the alloy can be done upon mild heating at $40^{\circ} \mathrm{C}$ and $1 \mathrm{MPa}$ pressure with an incubation time of $20 \mathrm{~h}$ (Liu and Suda, 1995). However, fluorination of $\mathrm{LaNi}_{5}$ 's surface has been found to readily facilitate the reactivation of the oxidized alloy without any incubation time. In this case, the fluorinated surfaces creates a protective layer around the alloy, i.e., $\mathrm{LaF}_{3}$, which selectively allows hydrogen to pass through it (Liu and Suda, 1995). Hence, the fluorinated alloy is immune to some extent against hydrogen impurities such as $\mathrm{O}_{2}, \mathrm{CO}$ and $\mathrm{CO}_{2}$ (Liu and Suda, 1995; Wang and Suda, 1995; Suda et al., 2001).

\section{$\mathrm{AB}_{2}$ and Solid-Solution Alloys}

In comparison to $\mathrm{LaNi}_{5}$ and its related systems, $A B_{2}$ alloys have relatively higher storage capacities, faster kinetics, longer cycle life and potential for lower costs (Bououdina et al., 2006). $A B_{2}$ type alloys are commonly obtained from $\mathrm{Ti}$ and $\mathrm{Zr}$ as the " $A$ " element, while the " $B$ " element includes $3 \mathrm{~d}$ metals such as V, Cr, Mn, Fe, and their combination (Sandrock, 1999; Sakintuna et al., 2007). $A B_{2}$ alloys exhibit Laves phases that are classified along three crystalline structures: cubic C15, hexagonal C14 and double hexagonal C36 (Bououdina et al., 2006). An example of such $A B_{2}$ materials is $\mathrm{TiMn}_{1.4} \mathrm{~V}_{0.62}$, which has a hydrogen storage capacity of $2.15 \mathrm{wt} \% \mathrm{H}_{2}$ (Sandrock, 1999). Vanadium has two hydrides $\mathrm{VH}_{\sim_{1}}$ and $\mathrm{VH}_{\sim 2}$ giving an appearance of two equilibrium plateau pressures (International Journal of Hydrogen Energy Reilly and Wiswall, 1970). Vanadium and vanadium-based solid-solutions with a bcc structure can absorb $3.8 \mathrm{wt} \% \mathrm{H}_{2}$ at RT. However, due to the lower plateau region falling below $1 \mathrm{~Pa}$ at ambient temperature, these hydrides can only desorb about half of the original absorption capacity (Okada et al., 2002).

To take advantage of the small hysteresis and the fast kinetics of $A B_{2}$ type alloys in combination with the higher storage capacity of solid-solution alloys, a synergetic mixture of Laves phase and BCC-type phase, i.e., Ti-V-Mn (2.1 wt $\% \mathrm{H}_{2}$ at ambient conditions) has been introduced by Akiba and Iba (1998) and (Okada et al., 2002). Such multi-phase alloys were investigated extensively by Iba and Akiba $(1995,1997)$ and (Akiba and Iba, 1998). Similarly, Ti-V40-Cr35\% alloy that has a desorption capacity of $2.4 \mathrm{wt} \% \mathrm{H}_{2}$ and its related composition were studied by Okada et al. (2002) to determine any trend between the absorption capacity and the alloy composition. it was reported that even at low vanadium content $(<35 \%)$, which is highly desirable due to high vanadium cost (Towata et al., 2013), high amounts of solid-solution bcc phases (primarily responsible for higher absorption capacity) were prevalent in the alloy.

\section{Hydrogen Cyclability of Current Room Temperature Hydrides}

Cyclic stability of $\mathrm{MH}$ is important when selecting an alloy for stationary applications (Wang et al., 2007; Selvaraj et al., 2018). Ideally, the hydrogen kinetics and the absorption/desorption properties of the metal hydride should not be altered during at least 10,000 cycles. Degradation of hydrogen properties after cycling can be the result of hydrogen impurities and/or a structural degradation, i.e., a disproportion of an unstable hydride phase into multiple stable phases (Broom, 2011). Disproportionation is manifested by changes in the PCT shape and/or losses in the hydrogen storage capacity (Sandrock et al., 1989). Such an effect has for example been reported to occur in $\mathrm{LaNi}_{5}$ and $\mathrm{Sm}_{2} \mathrm{Fe}_{17}$ (Goodell, 1984; Sugimoto et al., 2002; Shen and Perng, 2005). For example, Sandrock et al. (1989) observed significant disproportionation when $\mathrm{LaNi}_{5}$ was held at $180^{\circ} \mathrm{C}$ in its $\beta$ phase. It can be minimized by the increase of the binding energy between the metal atoms (Crivello and Gupta, 2003). To date, the most effective approach to solve the disproportion effects observed in $\mathrm{LaNi}_{5}$ is through partial substitution of $\mathrm{Ni}$ with $\mathrm{Sn}$, i.e., by forming $\mathrm{LaNi}_{5-x} \mathrm{Sn}_{x}$, where $x \approx 0.2$ (Bowman et al., 1995; Broom, 2011). $\mathrm{La}_{0.5} \mathrm{Ce}_{0.5} \mathrm{Ni}_{5}$ has shown excellent stability throughout 20,000 cycles at $15-160^{\circ} \mathrm{C}$, in comparison to $\mathrm{LaNi}_{5}$ exhibiting $>20 \%$ capacity loss due to disproportionation at the same conditions (Tarasov et al., 2018). Interestingly, Borzone et al. (2014) reported up to 1000 hydrogen cycles without any evidence of disproportionation for $\mathrm{LaNi}_{5}$ preserving $92 \%$ of its initial capacity. This is because disproportionation occurs only when the hydrogen pressure is above the plateau pressure of the metal hydride which is then accelerated due to repeated cycling and high temperatures (Sandrock et al., 1989). In the case of $\mathrm{LaNi}_{5}$, the effects of disproportionation at $180^{\circ} \mathrm{C}$ were drastically observed when the activated material was held at $13 \mathrm{MPa} \mathrm{H}_{2}$ instead of $6 \mathrm{MPa}$ (Sandrock et al., 1989). By cycling $\mathrm{LaNi}_{5}$ at a lower pressure of $8 \mathrm{MPa} \mathrm{H}_{2}$ at $43^{\circ} \mathrm{C}$ for absorption Borzone et al. (2014) observed negligible effects of disproportionation.

The $A B_{2}$ type alloy $\mathrm{Ti}_{0.98} \mathrm{Zr}_{0.02} \mathrm{~V}_{0.43} \mathrm{Fe}_{0.09} \mathrm{Cr}_{0.05} \mathrm{Mn}_{1.5}$ also showed no degradation up to 42,400 cycles with cycling temperatures at $45-120^{\circ} \mathrm{C}$ and pressure range of $2.6-3.3 \mathrm{MPa}$ while remaining its storage capacity at $1.24 \mathrm{wt} \% \mathrm{H}_{2}$ (Friedlmeier et al., 1995). Similarly, $\mathrm{Ti}_{1.1} \mathrm{CrMn}$ showed good cyclic properties with only a $6 \%$ loss in storage capacity, i.e., 1.8 wt $\% \mathrm{H}_{2}$ after 1000 cycles (Kojima et al., 2006). Also, Cho et al. (2007) showed that $\mathrm{Ti}_{0.32} \mathrm{~V}_{0.25} \mathrm{Cr}_{0.43}$ afforded 1000 cycles with a steady reversible capacity of $\sim 2 \mathrm{wt} \%$ at $30^{\circ} \mathrm{C}$ without any signs of disproportionation. However, Selvaraj et al. (2018) reported a degradation in the hydrogen properties of $\mathrm{Ti}_{32} \mathrm{~V}_{20} \mathrm{Cr}_{48}$ upon 100 cycles. This was attributed to the low content of vanadium disproportionating into other stable compositions, e.g., $\mathrm{Ti}_{32-\alpha}$ $\mathrm{V}_{20-\beta} \mathrm{Cr}_{48}$ where $\alpha$ and $\beta$ are related to the amount of the intermediate $\mathrm{TiH}_{0.66}$ and $\mathrm{VH}_{0.81}$ phases formed during hydrogen cycling, respectively. The exposure of the alloy to high temperatures, e.g., $>300^{\circ} \mathrm{C}$, may also explain the origin of such a disproportionation.

Based on these results, it is clear that unappropriated variations in the amount of $\mathrm{Ti}$ and $\mathrm{V}$, which form stable hydrides 
precipitates in the Ti-V-Cr solid solution, can have significant effects on the disproportionation mechanisms. Based on this, Shen and Li (2015) proposed that annealing treatment could benefit the elimination of segregation.

\section{SYNTHESIS METHODS OF ROOM TEMPERATURE HYDRIDES}

Generally, the synthesis of the $\mathrm{MH}$ occurs along 3 recurring steps: (i) the alloy formation, (ii) annealing/chemical/mechanical treatments, and (iii) activation of the alloy. However, other aspects can also be considered as a part of the synthesis process. This includes surface treatment for oxidation resistance or catalytic additives for lowering activation barrier for $\mathrm{H}_{2}$ sorption. Hence, during the synthetic process of the alloy, the properties of $\mathrm{MH}$ can be tailored to meet specific hydrogen properties. Some of the synthesis processes include arc and induction melting, mechanical milling, and cold rolling/torsion process that can be scaled up for large scale manufacturing. Methods including physical and chemical vapor deposition, thermolysis, chemical reduction, and electrochemical deposition remain manly labscale approaches (Sun et al., 2018).

Mechanically milling is among the relatively simple approaches to synthesizing alloys in large quantities (Abd.Khalim Khafidz et al., 2016). From the late 1980s, Ivanov et al. (1987) in particular, were among the first to use mechanical milling as a mean to synthesize $\mathrm{Mg}$-based alloys with $\mathrm{Co}, \mathrm{Cr}, \mathrm{Fe}$, and $\mathrm{Ni}$ addition (Song et al., 1987; Stepanov et al., 1987). The advantages of using mechanical milling reside in the possibility to: (i) synthesize new alloys from their respective elements and this may result in a modification of the hydrogen-metal bond strength, (ii) make nanostructures or amorphous materials, and (iii) through doping with catalytic additives improve the hydrogen kinetics (Broom, 2011; Abd.Khalim Khafidz et al., 2016). Modification by milling of the archetypal alloys and intermetallics such as $\mathrm{LaNi}_{5}$ (Corré et al., 1999; Liang et al., 2001a; Fujii et al., 2002), $\mathrm{MmNi}_{5}$-based (Ares et al., 2004; Singh et al., 2004), TiFe (Abe and Kuji, 2007; Hotta et al., 2007), Ti-V-Mn (Huot et al., 2008), Ti-Cr (Takeichi et al., 2004), Ti-V-Cr (Santos et al., 2004), and Mg-Ni (Orimo and Fujii, 1998; Orimo et al., 1999; Terashita et al., 1999) have been reported. Besides mechanical milling in inert atmosphere, to combine the effects of alloy formation and activation, the concept of reactive milling has also been used, where the materials are processed under $\mathrm{H}_{2}$ atmosphere. However, such steps can also modify the crystal structure of the $\mathrm{MH}$ and lead to amorphous phases, which inherently affect the hydrogen storage properties (Fujii et al., 2002; Santos et al., 2004). For instance, milling $\mathrm{LaNi}_{5}$ under $\mathrm{H}_{2}$ forms two phases: $\mathrm{LaNi}_{5} \mathrm{H}_{0.15}$ and amorphous phase initially and further milling can also lead to nanocrystalline $\mathrm{Ni}$ and amorphous $\mathrm{LaNi}_{y} \mathrm{H}_{z}(y<5)$ (Fujii et al., 2002). In contrast, reactive milling of $\mathrm{Ti}-\mathrm{V}-\mathrm{Cr}$ materials leads to a hydrogenation of the alloy under hydrogen (Santos et al., 2004).

Alloys that were previously only prepared by melting methods have also now being synthesized by mechanical milling. For examples, $\mathrm{Ti}_{50}-\mathrm{V}_{50}$ has been known to forms a BCC type structure upon arc melting. Upon ball milling $\mathrm{Ti}$ and $\mathrm{V}$ with some carbon as a process control agent, Li et al. (2019) reported a $\mathrm{Ti}_{50} \mathrm{~V}_{50}-10 \mathrm{wt} \% \mathrm{C}$ based alloy forming a unique FCC structure with a low packing density $\left(5.1 \mathrm{~g} \mathrm{~cm}^{-3}\right)$ and a crystalline size of $60 \mathrm{~nm}$. The packing efficiency of this FCC structure (52\%) is comparatively lower than that reported for other structures such as FCC (74\%), HCP (74\%), or BCC (68\%) and this possibly implies higher diffusion kinetics of $\mathrm{H}$ atoms as compared to hydrogen diffusion in the BCC lattice (Völkl and Alefeld, 1975; Li et al., 2019). TiVMn- and TiCrMn- based nano-alloys with FCC structure were also reported to form via mechanical milling (Li et al., 2018).

$A B$ type alloys, commonly TiFe, are also synthesized conventionally using the arc-melting process. However, due to the difficulty in the activation of the alloy mainly due to the surface oxidation (Reilly and Wiswall, 1974; Jai-Young et al., 1983; Schlapbach and Riesterer, 1983; Kulshreshtha et al., 1993; Inui et al., 2002), attempts have been made in exploring other synthesizes approach for TiFe that are activation-free. For example, approaches were employed such as a mixture of $\mathrm{O}_{2}$ and $\mathrm{H}_{2}$ atmosphere to precipitate titanium oxide and iron clusters (Züchner and Kirch, 1984) and mechanical alloying to form nanostructured TiFe (Trudeau et al., 1992; Haraki et al., 2008). Alternatively, hydriding combustion synthesis is another novel approach that has been used to prepare TiFe alloys (Saita et al., 2007). This synthesis approach involves igniting the material's precursors in pure hydrogen atmosphere and with the adiabatic flame temperature of the process as high as $1,800^{\circ} \mathrm{C}$, it has been possible to synthesize TiFe alloys (Li et al., 1999). Hydriding combustion synthesis has resulted in an improvement in the activation of TiFe by shortening the activation time drastically.

\section{INTEGRATION OF ROOM TEMPERATURE HYDRIDES IN TANKS}

The design of the metal hydride tanks plays a significant role in the performance of the $\mathrm{MH}$ to store hydrogen effectively at RT while enabling practical hydrogen uptake and release rates. Both the metal alloy and hydrogen contribute to design challenges in enabling fully functional solid-sate hydrogen storage tanks. This includes the packing density of the tank, the overall porosity of the hydride bed, and its thermal conductivity upon hydrogen uptake and release.

Upon hydrogen absorption, the exothermic reaction of hydrogen with the absorbing alloy generates heat that raises the operating temperature. If this heat is not dissipated quickly, the absorption rate reduces and thus the charging time (Mazzucco et al., 2014). The hydrogen desorption rates are similarly impacted due to the endothermic nature of hydrogen release from metal alloys. For example, it has been observed that for $\mathrm{Ti}_{0.98} \mathrm{Zr}_{0.02} \mathrm{~V}_{0.43} \mathrm{Fe}_{0.09} \mathrm{Cr}_{0.05} \mathrm{Mn}_{1.5}$, the operating pressure of the alloy falls below the minimum required inlet pressure of $170 \mathrm{kPa}$ (absolute) for the fuel cell system, although the equilibrium plateau pressure of this alloy is high $\left(1.1 \mathrm{MPa}\right.$ at $\left.25^{\circ} \mathrm{C}\right)$ (Sandrock, 1999; MacDonald and Rowe, 2006; Førde et al., 2009; Melnichuk et al., 2009; Tetuko et al., 2016). Such an observation has been 
attributed to problems of heat transfer within the tank that limits the desorption of hydrogen, leaving the tank full at $\sim 60 \%$.

In addition to the heat management of the metal/hydrogen reaction, additional consideration should be made in terms of the materials used for the tank itself and associated component because of the potential of hydrogen embrittlement observed in many materials (Walker, 2008).

\section{Managing Heat Transfer in Solid-State Tanks}

To bypass the problem of heat management, general design solutions can include: (i) oversizing the metal hydride tank and (ii) working at excessive hydrogen pressures to ensure that the hydrogen uptake still progresses despites the heat generated and subsequent increase of the equilibrium plateau pressure of the hydride and (iii) fragment the hydrogen storage tanks into multiple tanks of narrow cross section for effective heat dissipation. However, besides these simple solutions, other alternative solutions of heat integration have also been explored (Tetuko et al., 2016).

Alternatives for the desorption process such as heating the metal hydride bed above ambient temperatures by using waste heat recovered from fuel cell is often regarded as the effective approach because this is a neat way to facilitate the $\mathrm{H}_{2}$ desorption process from metal hydride tanks (Mellouli et al., 2007; Melnichuk et al., 2009; Dhaou et al., 2010). Examples of various thermal integration systems have been investigated in the past as shown in Figure 8, using waste heat either in the form of exhaust air or closed-loop water circulation systems.

Similarly, in the case of the absorption process, the waste heat generated from the exothermic reactions of absorption of $\mathrm{H}_{2}$ in the metal hydride bed can be effectively utilized as a thermal storage system. For example, $\mathrm{LaNi}_{5} \mathrm{H}_{6}$ has an enthalpy of formation $\approx 30 \mathrm{~kJ} \mathrm{~mol}^{-1} \mathrm{H}_{2}$, which gives $\approx 15 \mathrm{MJ}$ of heat when $1 \mathrm{~kg}$ of $\mathrm{H}_{2}$ is being absorbed (Abdin et al., 2018). This heat can be stored and redirected back to compensate for the endothermic reaction during the desorption process. For example, Jehan and Fruchart (2013) proposed McPhy-Energy system containing a self-regulating "adiabatic" type tank that can immediately deliver hydrogen to fuel-cell for electrical energy needs (Jehan and Fruchart, 2013).

The rate limiting step in the effectiveness of transferring waste heat from the metal hydride bed to the external environment is due to the poor thermal conductivity of $\mathrm{MH}$. For example, a $\mathrm{LaNi}_{5}$ powder bed has a very poor effective thermal conductivity of $\sim 1.32 \mathrm{~W} \mathrm{~m}^{-1} \mathrm{~K}^{-1}$ (Goodell and Rudman, 1983).
A

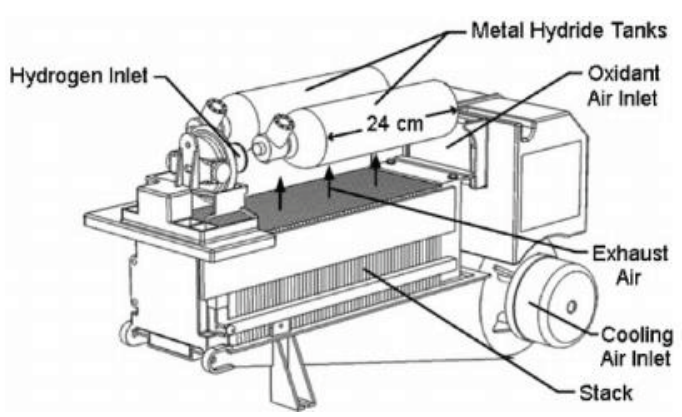

B

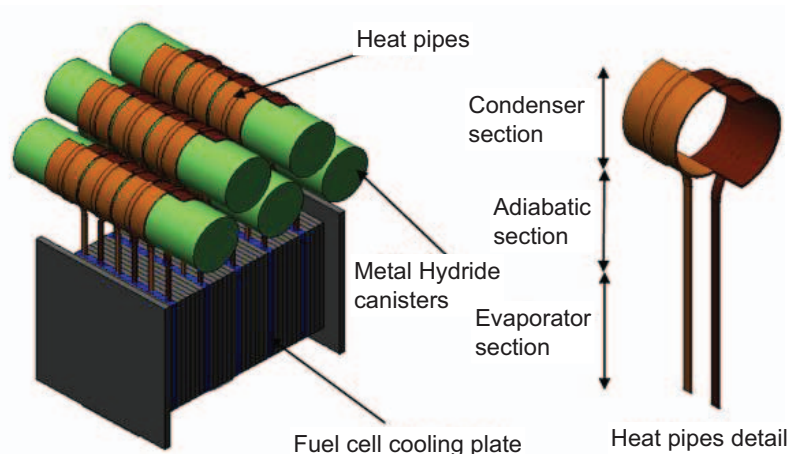

C

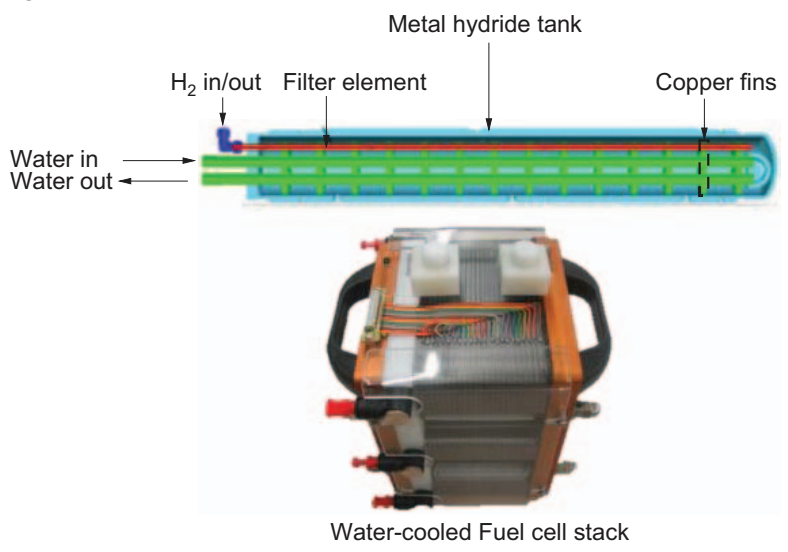

FIGURE 8 | Different thermal integration systems of feeding heat from fuel cell to metal hydride vessel. (A) Exhaust air transmitted via convection system from fuel cell stack (MacDonald and Rowe, 2006), (B) Heat transmitted via conduction system using heat pipes (Tetuko et al., 2016) and (C) Water-heated metal hydride tank using water circulation system from fuel cell stack (Førde et al., 2009). 
Many models have been developed in an attempt to facilitate the design of solutions for the heat management in metal hydride storage tanks. This includes $1 \mathrm{D}$ models to predict the weight fraction of hydrogen absorption and the metal hydride bed temperature (Mazzucco and Rokni, 2015), and 3D numerical models of heat and mass transfer prediction during hydrogen uptake/release including modeling the behavior of various forms of heat exchangers such as axial heat exchanger tubes, coiled heat exchanger tubes, external cooling and transversal heat distribution fins (Satya Sekhar et al., 2015). Four different heat exchange configurations were studied i.e., by natural convection, by fins, by internal concentric circulation fluid and by concentric fins, with cylindrical metal hydride tanks. The most efficient design out of the four configurations to achieve the lowest hydrogenation/dehydrogenation time was the concentric tube for fluid flow equipped by transverse fins (Askri et al., 2009; Mohammadshahi et al., 2016).

Designing metal hydride tanks includes modeling of the interaction between metal hydride bed and its surrounding. In an equilibrium state, this interaction can be formulated in the form of an energy balance to determine the heat-transfer mechanism in the metal hydride tanks. The equations for the energy balance would differ depending on the design of the tank and the integration of heat transfer medium. To take an example of a simple setup that involves metal hydride tank integrated with water recirculation loop system would have an energy balance as shown below (Førde et al., 2009):

$$
\begin{gathered}
\dot{Q}_{m}=\dot{Q}_{\text {reac }}+\dot{Q}_{H_{2}}+\dot{Q}_{W} \\
\dot{Q}_{m}=c_{p, \text { reactor }} m_{\text {reactor }} \frac{\partial T_{\text {reactor }}}{\partial T}+c_{p, M H} m_{M H} \frac{\partial T_{M H}}{\partial T} \\
\dot{Q}_{\text {reac }}=\dot{m}_{H_{2}} \Delta H \\
\dot{Q}_{H_{2}}=\dot{m}_{H_{2}, g} c_{p, H_{2}}\left|T_{\text {surrounding }}-T_{M H}\right| \\
\dot{Q}_{W}=\dot{m}_{W} c_{p, w}\left(T_{w, \text { in }}-T_{w, \text { out }}\right)
\end{gathered}
$$

where, $c_{p}$ is the heat capacity, $\mathrm{m}$ is mass, $T$ is temperature, $\dot{m}_{H_{2}}$ is the amount of $\mathrm{H}_{2}$ entering (absorption: " + ") or leaving (desorption: "-") the reactor, $\dot{m}_{W}$ is the flow rate of the circulating water, $\dot{Q}_{m}$ is heat flux for the change in temperature of reactor shell and metal hydride bed $\left(\mathrm{J} \mathrm{s}^{-1}\right) \dot{Q}_{\text {reac }}$ is energy produced/consumed in chemical gas-solid reaction $\left(\mathrm{J} \mathrm{s}^{-1}\right), \dot{Q}_{\mathrm{H}_{2}}$ is energy transferred in and out of the reactor with the $\mathrm{H}_{2}$ gas ( $J$ $\mathrm{s}^{-1}$ ) and $\dot{Q}_{W}$ is energy transferred in and out of the reactor with the heating and cooling of water $\left(\mathrm{J} \mathrm{s}^{-1}\right)$.

To reach the state of thermal equilibrium, one of the main barriers for effective heat transfer is the particle/particle interface heat conduction. This heat conduction can be quantitatively compared using the effective thermal conductivity $\left(K_{\text {eff }}\right)$ in the

\begin{tabular}{|c|c|c|}
\hline Materials & $\begin{array}{l}\text { Thermal conductivity (W } \\
\qquad \mathrm{m}^{-1} \mathrm{~K}^{-1} \text { ) }\end{array}$ & References \\
\hline \multicolumn{3}{|l|}{ Gas } \\
\hline Air & 0.026 & ToolBox, 2003 \\
\hline Argon & 0.016 & \\
\hline Helium & 0.142 & \\
\hline Hydrogen & 0.168 & \\
\hline \multicolumn{3}{|l|}{ Metals } \\
\hline Al & 247 & Lias et al., 2016 \\
\hline Al foam & 11 & Mellouli et al., 2009 \\
\hline $\mathrm{Cu}$ & 398 & Lias et al., 2016 \\
\hline $\mathrm{Fe}$ & 80 & Lias et al., 2016 \\
\hline Graphite & 130 & $\begin{array}{c}\text { Azeem and } \\
\text { Zain-ul-Abdein, } \\
2012\end{array}$ \\
\hline $\mathrm{Na}$ & 128 & Bird et al., 2020 \\
\hline $\mathrm{Ni}$ & 90 & Lias et al., 2016 \\
\hline W & 178 & Lias et al., 2016 \\
\hline \multicolumn{3}{|l|}{ Alloys } \\
\hline 1,025 Steel & 52 & Lias et al., 2016 \\
\hline 316 Stainless steel & 16 & Lias et al., 2016 \\
\hline Brass & 121 & Askri et al., 2009 \\
\hline $\mathrm{LaNi}_{5}$ & 2.4 & Mellouli et al., 2009 \\
\hline $\mathrm{LaNi}_{4.7} \mathrm{Al}_{0.3}$ - compacted & 13 & Haller, 1988 \\
\hline $\mathrm{MmNi}_{4.5} \mathrm{Al}_{0.5}+\mathrm{Al}$ foam & 4 & Suda, 1985 \\
\hline $\mathrm{TiMn}_{1.5}$ & 0.25 & Suda et al., 1980 \\
\hline $\mathrm{TiFe}+17 \mathrm{wt} \% \mathrm{Al}$ & 13 & Groll, 1993 \\
\hline $\mathrm{TiFe}+\mathrm{Mg}$ matrix & 11 & Groll, 1993 \\
\hline
\end{tabular}
form of $\mathrm{W} \mathrm{m}^{-1} \mathrm{~K}^{-1}$, which has been tabulated in Table 6 for materials involved in hydrogen storage. For achieving fast absorption/desorption rates, high thermal conductivity of the
TABLE 6 | Thermal conductivity values of materials related to hydrogen storage.

material in the bed is necessary. However, in practical scenarios a high thermal conductivity across the hydride bed alone is not sufficient because the thermal conductivity of the individual "elements", i.e., the hydrogen gas, its pressure, the material of the tank, and heat sinks, etc.; can all affect the heat flux (Figure 9; Wakao and Vortmeyer, 1971).

To illustrate this heat transfer concept, the relationship between effective thermal conductivity and pressure can be used, as it has been reported to follow a typical S-shaped curve (Wakao and Vortmeyer, 1971; Suda et al., 1980, 1983; Nagel et al., 1986; Hahne and Kallweit, 1998; Wu et al., 2009; Kan et al., 2015; Mazzucco and Rokni, 2015). The impact of individual "elements" on this S-shaped curve can be wellunderstood using the example of a tank that has a metal hydride such as $\mathrm{MmNi}_{4.5} \mathrm{Al}_{0.5}$ alloy embedded in a copperwire matrix (Nagel et al., 1986) as represented on Figure 9A. At a low hydrogen pressure $(<0.02 \mathrm{MPa})$, a low effective thermal conductivity of $K_{\text {eff }} \sim 0.3-0.4 \mathrm{~W} \mathrm{~m}^{-1} \mathrm{~K}^{-1}$ is observed (Figure 9A-i; Wakao and Vortmeyer, 1971). At intermediate pressures of $0.02-3 \mathrm{MPa}$, the effective thermal conductivity of typical $\mathrm{MH}$ evolves into an S-shaped curve. To isolate the heat generated under the influence of gas pressure built-up, helium gas can be used because of its inertness toward the hydride forming metal and a thermal conductivity close to that of hydrogen $\left(K_{H 2}=K_{H e} \times 1.25\right.$, where $K_{H 2}$ and $K_{H e}$ represent the effective 
A

(i)

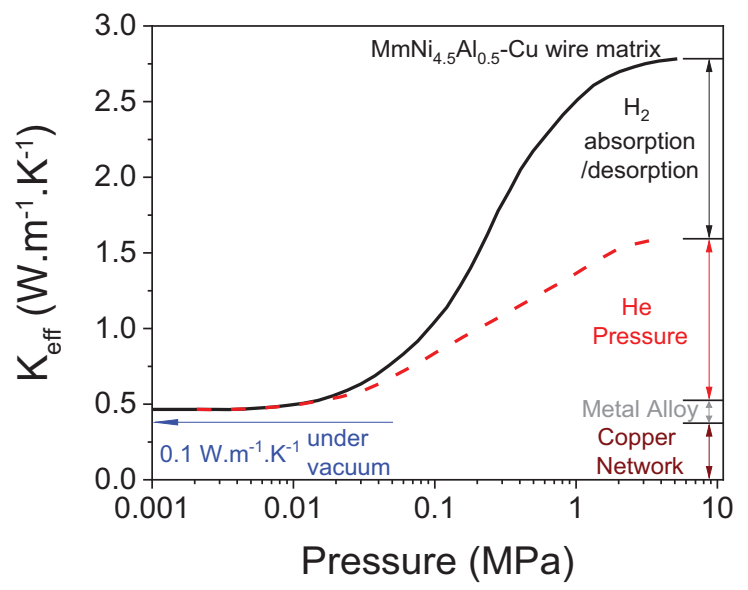

(ii)

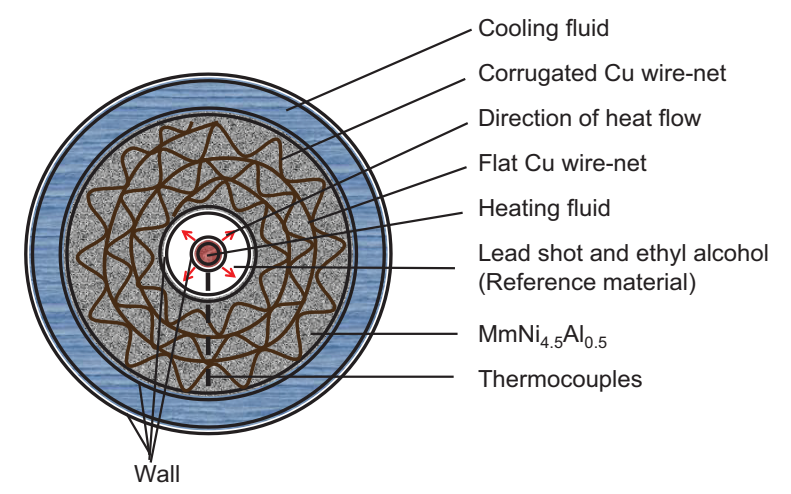

B

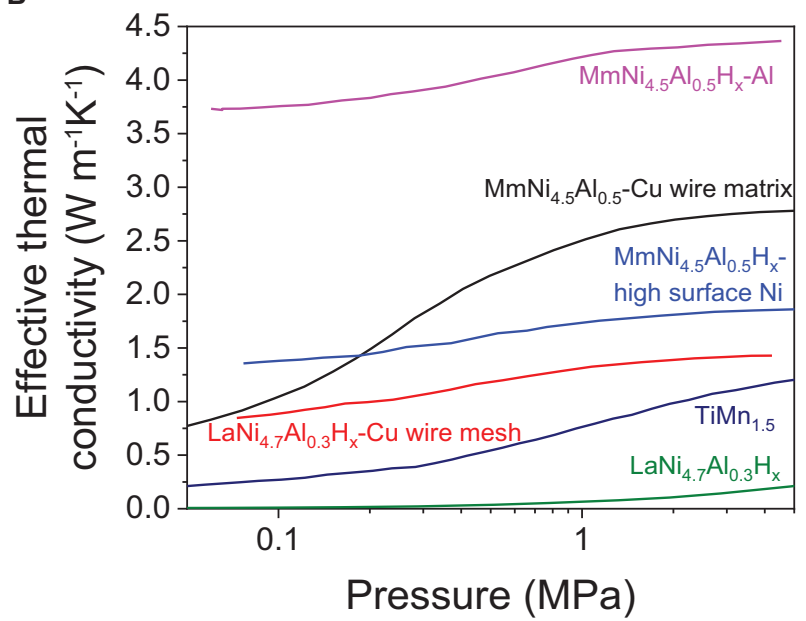

FIGURE 9 | Effective thermal conductivity ( $\mathrm{K}_{\text {eff }}$ ) curve of (A) (i) $\mathrm{MmNi}_{4.5} \mathrm{Al}_{0.5}$ under varying pressures formed due to $\mathrm{H}_{2}$, He insertion, metal alloy and copper network and (ii) its related structural model of the tank with the copper wire matrix (Nagel et al., 1986). (B) Effective thermal conductivity curves of various metal hydrides with/without using thermal enhancements (Suda et al., 1980, 1983; Nagel et al., 1986).

thermal conductivity under hydrogen and helium atmosphere, respectively). By separating the heat from the gas-pressure built up and that related to the entire system, the heat generated by the hydride formation only can be deduced (Figure 9A-i). Although a major influence on the $K_{\text {eff }}$ is observed from $\mathrm{H}_{2}$ gas absorption/desorption in metals $\left(>1.2 \mathrm{~W} \mathrm{~m}^{-1} \mathrm{~K}^{-1}\right.$ ) (Figure 9Ai), the ability to improve $K_{\text {eff }}$ by optimizing this parameter is limited by $\Delta \mathrm{H}^{\theta}$, because the later must remain within -10 to $-60 \mathrm{~kJ} \mathrm{~mol}^{-1} \mathrm{H}_{2}$ for the RT hydrides to be reversible (Sandrock, 1999; Bérubé et al., 2007). This suggests that the additional parameters including the gas pressure, the type of metal alloy and the thermal additives used, are the only additional means to control heat management upon hydrogen uptake and release

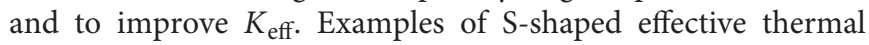
conductivity curves of various other $\mathrm{MH}$ with/without additives are also reported (Figure 9B).
In current investigations, efforts have been driven toward using additives with high thermal conductivity to improve the heat transfer and compensate for the low contact between the hydride particles and their poor thermal conductivity. For example, a typical thermal conductivity factor of $K_{\text {eff }} \approx 0.1 \mathrm{~W} \mathrm{~m} \mathrm{~m}^{-1} \mathrm{~K}^{-1}$ is observed for $\mathrm{RT} \mathrm{s}$ hydrides like $\mathrm{Ca}_{0.4} \mathrm{Mm}_{0.6} \mathrm{Ni}_{5}$ (Kim et al., 1998) where additives to improve the thermal conductivity of the hydride bed include corrugated copper wires (thermal conductivity of $389 \mathrm{~W} \mathrm{~m}^{-1} \mathrm{~K}^{-1}$ ) (Nagel et al., 1986), copper-encapsulated metal hydride compact discs (cooling output of approx. $0.8 \mathrm{~kW} \mathrm{~kg}^{-1}$ for $\mathrm{Ca}_{0.4} \mathrm{Mm}_{0.6} \mathrm{Ni}_{5}$ ) (Kim et al., 1998), the addition of expanded graphite (Kim et al., 2001) or insertion of aluminum foam (Lévesque et al., 2000). Other design solutions include that installation of heat exchangers around or across the hydride bed (Lévesque et al., 2000). 


\section{Tank Design}

Besides the thermal conductivity of the metal hydride bed as discussed above, the performance of the metal hydride system also depends upon the tank design including heat exchangers configurations, geometrical distribution of the metal hydride in the tank, and tank material and dimensions (Shafiee and McCay, 2016). Although multiple design variations of hydride tanks have been proposed, the basic geometrical configuration of tanks remains the same, i.e., a typical cylindrical structure (Shafiee and McCay, 2016). An example of such a tank structure is shown in Figure 10A using $\mathrm{LaNi}_{5}$ as the storage material (Jemni et al., 1999). To visualize the heat transfer across this metal hydride bed, Wang et al. (2009) performed 3-D modeling and presented a cross-section of the temperature contours at times from 1 to $2000 \mathrm{~s}$ (Figure 10B). Upon hydrogen absorption, initially, the temperature of the metal hydride bed evolves uniformly but then varies greatly across the hydride bed due to its poor

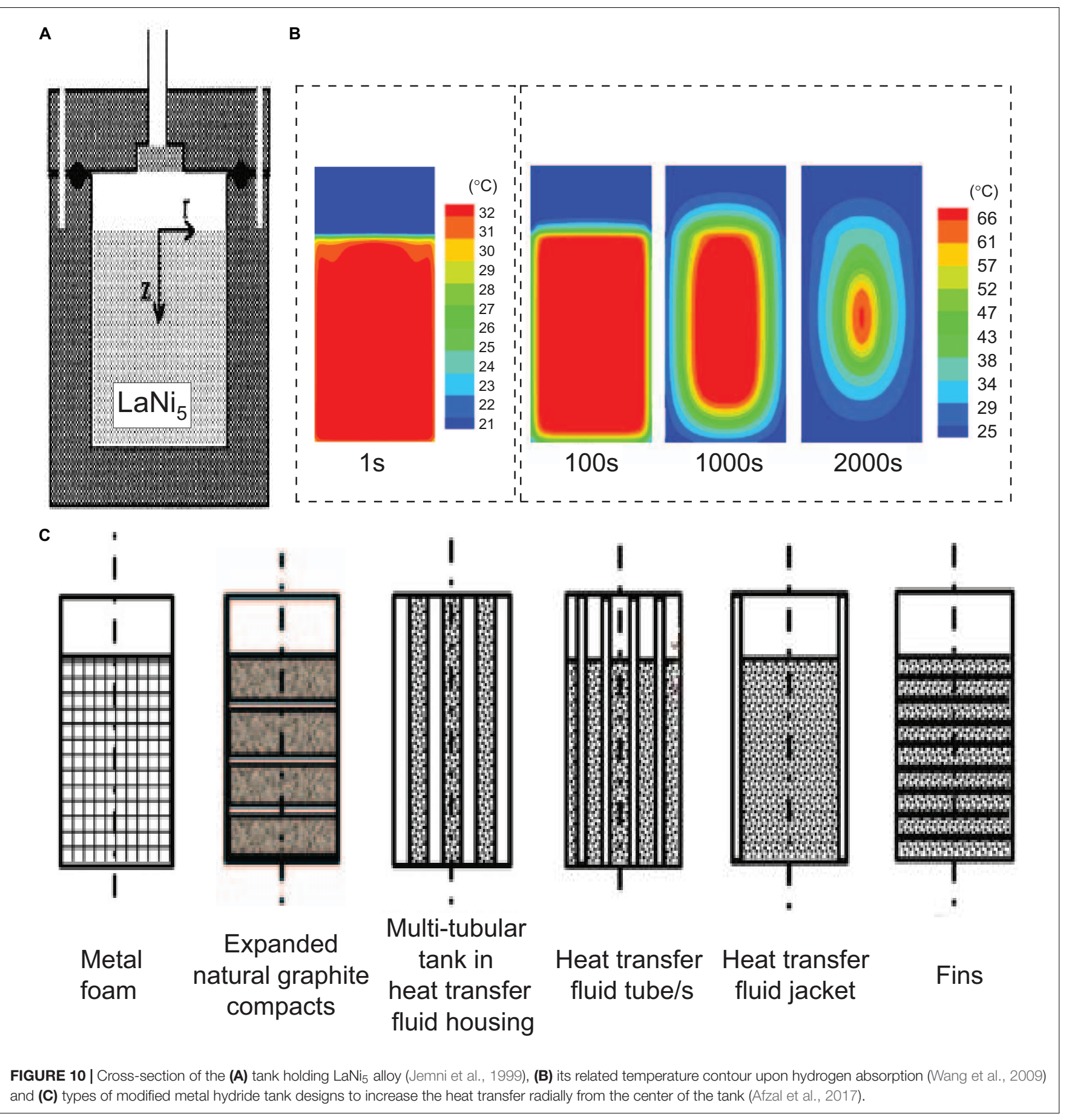


thermal conductivity. The incorporation of metal foams, tubular heat exchangers can help to some extent reduce the temperature heterogeneity across the hydrogen bed, but this is at the expense of the practical hydrogen volumetric and gravimetric storage capacity (Afzal et al., 2017).

To highlight the effects of modifications of the tank design on the heat transfer process, a simplified equation that is governed by how well the heat is conducted through the tank can be used (Afzal et al., 2017):

$$
\dot{Q}=K_{\mathrm{eff}} A \frac{\triangle T}{\triangle x}
$$

where, $\dot{Q}$ is the rate of heat transfer, $K_{\text {eff }}$ is the effective thermal conductivity of the material, $\Delta x$ is the distance for the heat to propagate through the medium and $\mathrm{A}$ is the surface area in contact.

Using eq. 9, the modifications on the tank design can be directly correlated to the factors that govern the heat transfer process. For example, metal foams and expanded natural graphite enhance the $K_{\text {eff }}$ parameter, multi-tubular tank reduces the distance $\Delta x$ for the heat to conduct through and heat transfer fluid tubes/jacket and fins increase the surface area for the heat to transfer (Afzal et al., 2017).

A safety concern that needs to be acknowledged is the possibility of generating stresses on the walls due to swelling of the metal hydride during hydrogen absorption when filling densities are high. It has been reported that localized stress has been generated at the bottom of the vessel when alloy packing fraction of $50 \mathrm{vol} \%$ which continues to increase with each cycle even after plastic deformation (Nasako et al., 1998). To mitigate this risk, solutions such as installing the cylindrical tank horizontally instead of vertically to exhibit less strain during hydrogenation, optimizing hydrogen content and packing fraction should be devised (Qin et al., 2008).

A safety concern that also needs to be addressed for the tank design is hydrogen embrittlement. Embrittlement typically occurs due to the hydrogen molecules readily dissociating into atomic hydrogen at metal surfaces, and permeate through the tank wall, to form solid-solutions in the metal lattice and this facilitates local crack formation and the fracture of the tank wall (Birnbaum, 1987, 2003; Gangloff, 2003; Walker, 2008). Austenitic stainless steel and metals such as $\mathrm{Cu}, \mathrm{Au}, \mathrm{Ni}$, and $\mathrm{Al}$ that have FCC structures tend to have low hydrogen permeability compared to BCC metals such as low-alloy and carbon steels (Walker, 2008). The rate of hydrogen permeation is expected to increase at higher surface area and elevated temperatures as shown by Figure $\mathbf{1 1}$ for various alloys and metals. A comprehensive study on high temperature permeability have also been recently reported (Sheppard et al., 2019). Typical susceptibility to hydrogen embrittlement of common metals/alloys as per ISO/TR 15916 standard is tabulated in Table 7 (ISO, 2004). Besides the tank body, these materials can also be used to manufacture the valves and various components to ensure compatibility throughout the system (ISO, 2012).

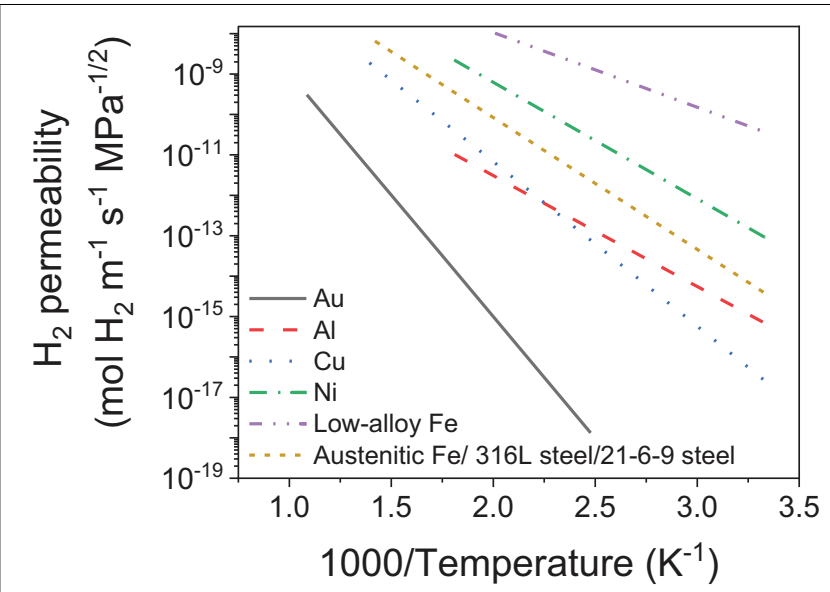

FIGURE 11 | Hydrogen permeability of various alloys and metals as a function of temperature. Austenitic $\mathrm{Fe}$ is an average of austenitic stainless steels such as 316 L steel and 21-6-9 steel (Louthan and Derrick, 1975; Xiukui et al., 1989); low-alloy Fe is 4130 quenched and tempered (Nelson and Stein, 1973) and pure metals i.e., Au (Begeal, 1978), Al (Song et al., 1997), Cu (Begeal, 1978), and Ni (Louthan et al., 1975). [Reproduced from Walker (2008)].

TABLE 7 | Hydrogen embrittlement susceptibility of commonly used metals/alloys (ISO, 2004).

\begin{tabular}{lc}
\hline Slightly embrittled & Negligibly embrittled \\
\hline - Carbon steel & $\bullet$ Aluminum alloys \\
1,020 & 1,100 \\
1,042 (normalized) & $6,061-$ T6 \\
- Stainless steel & $7,075-$ T73 \\
310 & $\bullet$ Be-Cu alloy 25 \\
316 & $\bullet$ Copper, OFHC \\
- Titanium & $\bullet$ Stainless steel \\
& A286 \\
\hline
\end{tabular}

\section{Alternative Hybrid High-Pressure System}

Using $\mathrm{MH}$-filled vessel gives the benefit of high volumetric hydrogen density (>90 $\mathrm{H}_{2-} \mathrm{kg} \mathrm{m}^{-3}$ ). However, with conventional RT hydrides, the gravimetric hydrogen density remains low. For example to store $5 \mathrm{~kg}$ of $\mathrm{H}_{2}, 167 \mathrm{~kg}$ of an alloy ( $3 \mathrm{wt} \% \mathrm{H}_{2}$ ) would be required and this would lead to an overall system of at least $200 \mathrm{~kg}$ once material is integrated to a tank with a heat exchanger (2.5 wt $\% \mathrm{H}_{2}$ at system level) (Takeichi et al., 2003). In an attempt to overcome this, the concept of "hybrid hydrogen storage vessel" combining a light-weight pressure vessel with a hydrogen pressure of 10-30 $\mathrm{MPa}$ and a hydrogen storage alloy with a high equilibrium hydrogen pressure has been proposed (Figure 12; Takeichi et al., 2003). For example, by integrating TiFe with a high-pressure system, a high gravimetric capacity of $5.4 \mathrm{wt} \%$ at the system level has been reported (Takeichi et al., 2003). In comparison, the low-pressure conventional metal hydride system using the same TiFe alloy would achieve a storage capacity of $\sim 1-2 \mathrm{wt} \% \mathrm{H}_{2}$ at the system level. Also, this hybrid approach provides flexibility in selecting $\mathrm{MH}$ with high desorption plateau pressure such as $\mathrm{TiCr}_{1.5} \mathrm{Mn}_{0.1} \mathrm{Fe}_{0.4}(\sim 10 \mathrm{MPa})$ and thus possibly reduce the 


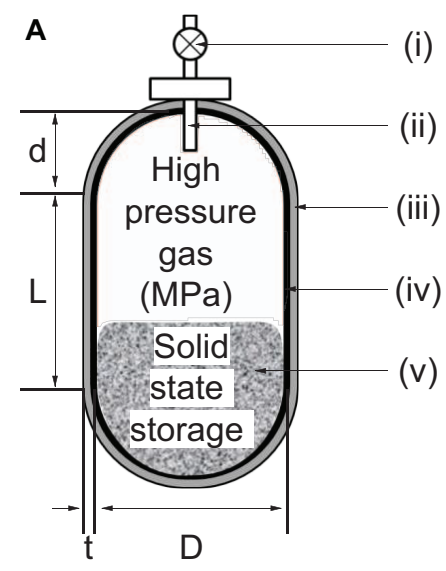

B

\begin{tabular}{lcc}
\hline Hydrogen properties & Units & Target \\
\hline Hydrogen storage capacity & $\mathrm{wt} . \%$ & $>3$ \\
Reaction enthalpy $(\Delta \mathrm{H})$ & $\mathrm{kJ} / \mathrm{mol}$ & $<20$ \\
Desorption equilibrium pressure at $-30^{\circ} \mathrm{C}$ & $\mathrm{MPa}$ & $>1$ \\
Absorption equilibrium pressure at $120^{\circ} \mathrm{C}$ & $\mathrm{MPa}$ & $<35$ \\
Degradation at 1000 cycles & $\%$ & $<10$
\end{tabular}

FIGURE 12 | Hybrid hydrogen storage vessel: (A) Schematic representation of novel hybrid hydrogen vessel were (i) valve, (ii) tube for hydrogen, (iii) carbon fiber and epoxy resin, (iv) thin aluminum liner and (v) hydrogen storage material such as $\mathrm{TiFe}$ and $\mathrm{TiCr}_{57.5} \mathrm{~V}_{5}$ (Takeichi et al., 2003); (B) Table showing estimated target values of hydrogen storage materials for hybrid high-pressure vessel (Mori et al., 2005; Shibuya et al., 2008).

dependence on temperature to ensure that the pressure plateau stays above atmospheric pressure while releasing hydrogen from the hydride (Chen et al., 2013). Other examples of $\mathrm{MH}$ reported in literature for hybrid high pressure vessel are $\mathrm{Ti}_{1-x} \mathrm{~V}_{x} \mathrm{Mn}$, where $x=0.3,0.5$, and 0.6 (Shibuya et al., 2008), $\mathrm{Ti}_{1+x} \mathrm{Cr}_{1.1} \mathrm{Mn}_{0.3} \mathrm{Fe}_{0.6}$ where $x=0,0.02$ and 0.04 (Chen et al., 2013), $\operatorname{TiCr}_{57.5} \mathrm{~V}_{5}$ (Takeichi et al., 2003) and TiFe (Takeichi et al., 2003). In addition, the selection of hydrides can be further extended to amorphous alloys like $\mathrm{Ti}_{1-x} \mathrm{Ni}_{x}, \mathrm{Zr}_{1-x} \mathrm{Ni}_{x}$ and $\mathrm{Y}_{1-x} \mathrm{Fe}_{x}$ (where $0.4 \leq \times \leq 0.55$ ) that do not have plateau pressures (Broom, 2011) and multiple crystalline phase alloys that can be mixed to form a multi-step plateau pressure providing control overpressure level for hydrogen supply.

Further investigations are needed along the design challenges associated with the concept of hybrid hydrogen storage vessels. For example, a trade-off exists between increasing the amount of metal hydride for enabling higher volumetric energy density and decreasing this amount for higher mass energy density. Stationary applications would typically prioritize volumetric energy density over mass energy density to reduce the cost associated with a square meter of land use (Choi et al., 2010). Therefore, achieving higher volumetric energy density, would favor hybrid vessels completely filled with the metal alloy. However, hybrid vessel that contains at least $10-50 \%$ of the metal alloy would require a well-designed heat exchanger and large flow of heat exchange mediums since the storage kinetics would be limited by the rate of the thermal evolution from the hydrogenation of the alloy (Takeichi et al., 2003). It is currently difficult to determine if the complexity in the heat exchange system increases or decreases in comparison to the low-pressure metal hydride tank. This is because of the trade-off between the selection of heat-exchange materials capable of withstanding high operating pressures of $10-30 \mathrm{MPa}$ and the need of reducing the balance of components due to low amount of metal alloy present in the hybrid vessel.

\section{AN ALTERNATIVE APPLICATION OF HYDRIDES IN STATIONARY APPLICATIONS}

Metal Hydrides have a distinct advantage of being considered carriers for both heat and hydrogen. In thermal storage application, the heat of the reaction liberated during the exothermic reaction of the hydride formation can serve as useful heat (Sheppard et al., 2016). Thereby hydrogen storage materials can be used as thermal storage solutions: (1) in a closed system in which $\mathrm{H}_{2}$ is preserved and is re-used during the heat storage cycles, or (2) in open systems in which $\mathrm{H}_{2}$ is released from a high-temperature hydride and is used for gas-to-heat/power application ( $\mathrm{H}_{2}$ combustion) (Felderhoff and Bogdanović, 2009).

A thermal storage system based on a closed system is illustrated in Figure 13A. For this system being used in conjunction with renewable energy sources, it is assumed that the heat required is initially generated from a concentrated solar power plant (Corgnale et al., 2014; d'Entremont et al., 2017). In this case, (i) during daytime hydrogen is released from a hightemperature hydride receiving heat from the concentrated solar plant into a secondary storage vessel; (ii) at night time, useful heat is then generated from the exothermic absorption of hydrogen in the high-temperature hydride. $\mathrm{TiH}_{2}, \mathrm{Zr}$ based $\mathrm{MH}, \mathrm{MgH}_{2}$ and Mg-based $\mathrm{MH}$ could be suitable for thermal storage purposes because they store hydrogen at suitable high temperatures for solar thermal applications, i.e., $300-1000^{\circ} \mathrm{C}$ and have a high enthalpy of formation (Figure 13B; Pelay et al., 2017; Yartys et al., 2019; Poupin et al., 2020). Another example of a metal hydride that can perform as thermal battery is calcium hydride $\left(\mathrm{CaH}_{2}\right)$. This is because of its high heat of formation of $4,312 \mathrm{~kJ} \mathrm{~kg}^{-1}$ at $25^{\circ} \mathrm{C}$, low operating pressures $(0.1-0.5 \mathrm{MPa})$ and a high heat storage capacity of $4,494 \mathrm{~kJ} \mathrm{~kg}^{-1}$ at $950^{\circ} \mathrm{C}$ (Manickam et al., 2019; Balakrishnan et al., 2020; Sofianos et al., 2020). However, the challenge is to reduce the decomposition temperature of $\mathrm{CaH}_{2}$ 


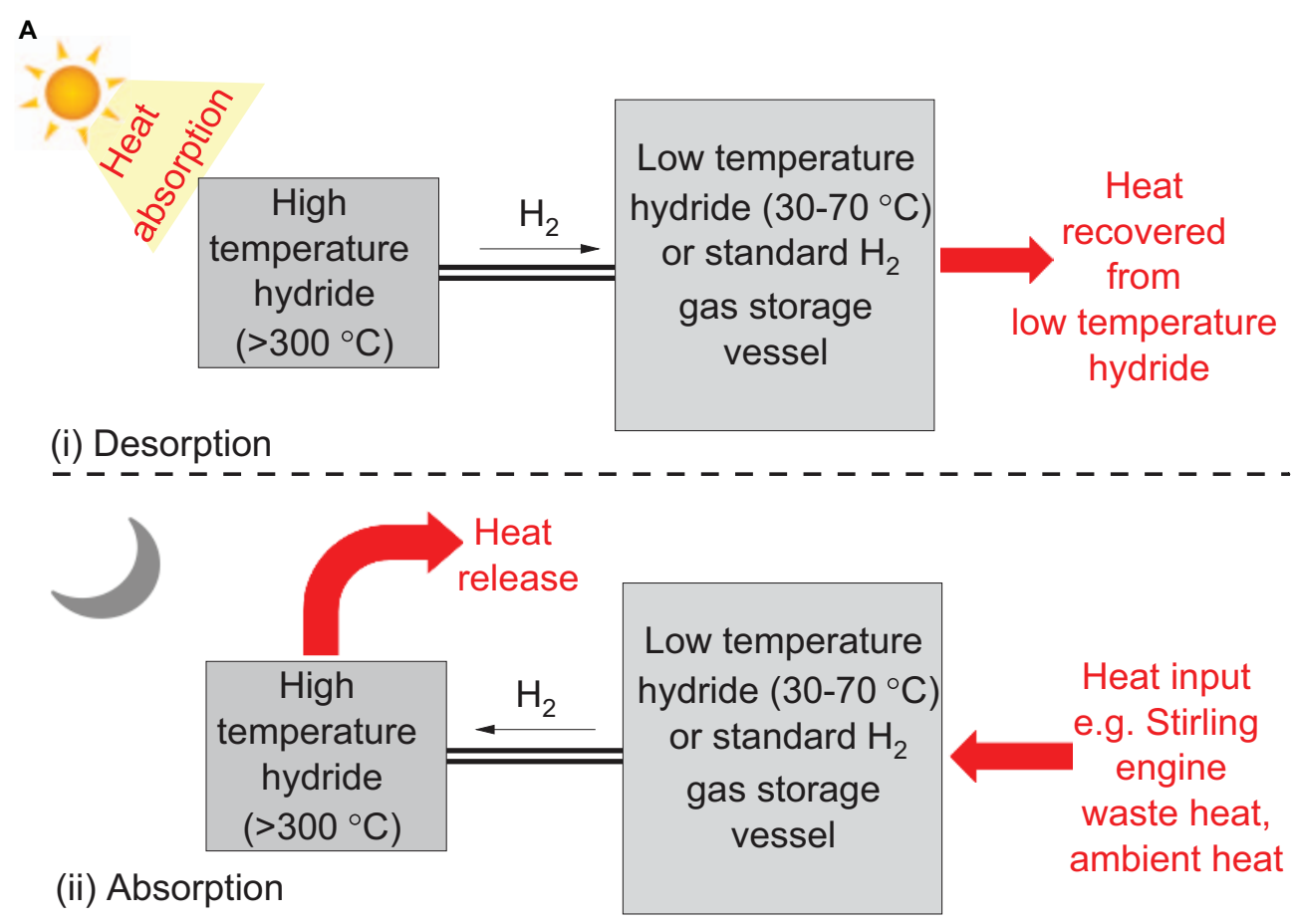

B

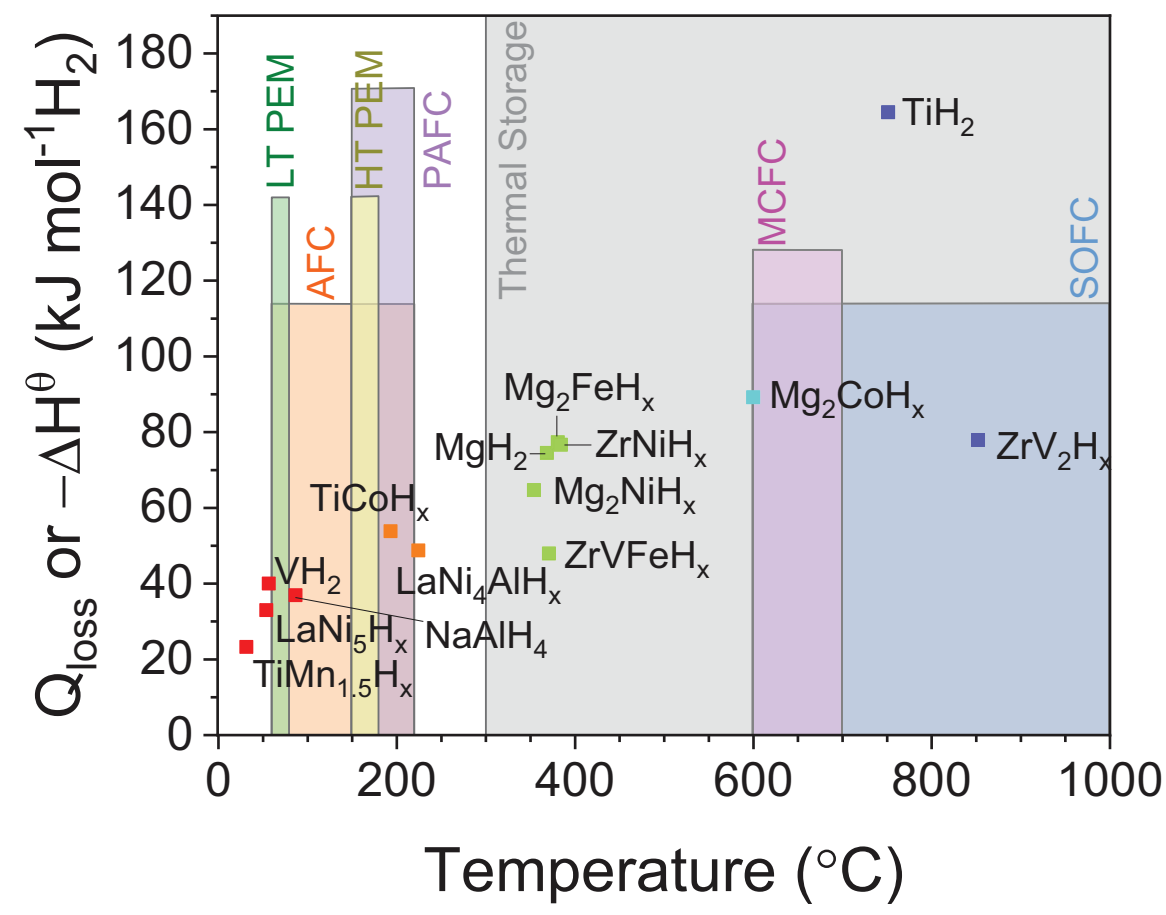

FIGURE 13 | (A) Schematic representation of using high-temperature hydrides in a closed system for thermal storage purposes under two scenarios: (i) desorption and (ii) absorption process where $\mathrm{H}_{2}$ is being released and absorbed from high-temperature hydride, respectively (Felderhoff and Bogdanović, 2009); (B) Evaluation of various metal hydrides with different fuel cell systems and their potential for being used as a thermal storage hydride. The desorption temperature values for metal hydrides are measured at $1 \mathrm{MPa}$ plateau pressure. Qloss is associated with heat loss from fuel-cell systems, while $-\Delta \mathrm{H}^{\theta}$ represents the enthalpy of formation of the presented hydrides (Lototskyy et al., 2017; Pelay et al., 2017). For thermal storage applications, the high-temperature hydrides such as $\mathrm{MgH}_{2}$ or $\mathrm{TiH}_{2}$ can be linked to low-temperature hydrides such as $\mathrm{TiMn}_{1.5} \mathrm{H}_{x}$ and $\mathrm{LaNi}_{5} \mathrm{H}_{x}\left(\Delta \mathrm{H}^{\theta} \approx 1 / 3\right.$ of high-temperature hydride) or a standard $\mathrm{H}_{2}$ pressure vessel that can be used as temporary storage of hydrogen (Felderhoff and Bogdanović, 2009). 
as its operating temperature is $>1,000^{\circ} \mathrm{C}$ and the cost associated with expensive containment vessels since both $\mathrm{Ca}$ and $\mathrm{CaH}_{2}$ are highly corrosive (Curtis and Chiotti, 1963; Wang et al., 2012). Therefore, to destabilize $\mathrm{CaH}_{2}$, additives such as $\mathrm{Al}$ and $\mathrm{Al}_{2} \mathrm{O}_{3}$ have also been explored that form a multi-step reactions for $\mathrm{CaH}_{2}$ decomposition (Balakrishnan et al., 2020).

Similar to thermal storage, another application for these hightemperature hydrides is to use them in combination with high operating temperatures fuel cell systems such as solid-oxide fuel cell (SOFC) and molten carbonate fuel cell (MCFC). This combination allows the utilization of high-temperature hydrides by recovering the heat loss $\left(Q_{\text {loss }}\right)$ from fuel-cell to facilitate the release of hydrogen from these hydrides. For example, $\mathrm{ZrV}_{2} \mathrm{H}_{x}$ high temperature hydride can be coupled with SOFC fuel cell and $\mathrm{Mg}_{2} \mathrm{CoH}_{x}$ can be coupled with both SOFC and MCFC as represented in Figure 13B (Felderhoff and Bogdanović, 2009). Although low-temperature hydrides such as $\mathrm{TiMn}_{1.5}, \mathrm{LaNi}_{5}$, $\mathrm{VH}_{2}, \mathrm{TiCoH}_{2}, \mathrm{NaAlH}_{4}$, and $\mathrm{LaNi}_{4} \mathrm{AlH}_{x}$ are all suitable for lowtemperature proton exchange membrane (LT PEM), alkaline fuel cell (AFC), high-temperature proton exchange membrane (HT PEM) and phosphoric acid fuel cell (PAFC), however, the beauty of designing the stationary systems is the amount of flexibility that can introduced into the system such that low-temperature hydrides can also be used for SOFC and MCFC conditions. For example, when the operating temperature of the fuel cell is higher than the required desorption temperature for metal hydride then the excess waste heat from fuel cell can be used for thermal applications (Pasini et al., 2013; Lototskyy et al., 2017).

\section{CONCLUSION}

With growing awareness of climate change and deployment of new intermittent renewable energy sources, hydrogen storage can be at the forefront of energy storage solutions. However, to successfully commercialize hydrogen storage solutions, it is vital to have the proper selection of $\mathrm{MH}$ that meets the requirements of stationary applications. Although generally, the selection criteria

\section{REFERENCES}

Abd.Khalim Khafidz, N. Z., Yaakob, Z., Lim, K. L., and Timmiati, S. N. (2016). The kinetics of lightweight solid-state hydrogen storage materials: a review. Int. J. Hydrogen Energy 41, 13131-13151. doi: 10.1016/j.ijhydene.2016.05.169

Abdin, Z., Webb, C. J., and Gray, E. M. (2018). One-dimensional metal-hydride tank model and simulation in Matlab-Simulink. Int. J. Hydrogen Energy 43, 5048-5067. doi: 10.1016/j.ijhydene.2018.01.100

Abe, M., and Kuji, T. (2007). Hydrogen absorption of TiFe alloy synthesized by ball milling and post-annealing. J. Alloys Compds. 446-447, 200-203. doi: 10.1016/j. jallcom.2006.12.063

Afzal, M., Mane, R., and Sharma, P. (2017). Heat transfer techniques in metal hydride hydrogen storage: a review. Int. J. Hydrogen Energy 42, 30661-30682.

Akiba, E., and Iba, H. (1998). Hydrogen absorption by Laves phase related BCC solid solution. Intermetallics 6, 461-470. doi: 10.1016/S0966-9795(97)00088-5

Ares, J. R., Cuevas, F., and Percheron-Guégan, A. (2004). Influence of thermal annealing on the hydrogenation properties of mechanically milled $\mathrm{AB}_{5}$-type alloys. Mat. Sci. Eng. B Solid 108, 76-80. doi: 10.1016/j.mseb.2003.10.083

Askri, F., Salah, M. B., Jemni, A., and Nasrallah, S. B. (2009). Optimization of hydrogen storage in metal-hydride tanks. Int. J. Hydrogen Energy 34, $897-905$. fall toward a specific category of intermetallic hydrides, however, the wide variety of $\mathrm{MH}$ with their various properties makes the selection process highly challenging. In addition, different intermetallic hydrides are prone to limitations and have unique ways of overcoming those limitations.

In recent years, new intermetallic hydrides with various compositions are being investigated and studied. This allows broadening the spectrum of metal hydride selection for hydrogen storage. New synthesis approaches have further enabled us to explore even past $\mathrm{MH}$ with a new perspective on their characteristic properties. The synergy of $\mathrm{Mg}$ and intermetallics, hybrid high-pressure vessels, reactive-milling and mixture of different crystal structures (Laves with BCC) have shown improvements in overcoming past limitations. However, further work needs to be carried out in optimizing these synergetic effects with a focus toward finding a pattern that can determine the optimal composition for metal hydride suitable for stationary applications. Additionally, optimal system design needs to be explored to create a thermal integration of fuel cell and intermetallic hydride. Such designs can then be extended to high-temperature hydrides for thermal storage purposes.

The main challenges toward meeting the targets of stationary applications is the lack of understanding of which method or process is favorable for improving the properties of hydrogen storage material. With this paper, we have managed to address this issue up to a certain extent. However, certain areas still have to be explored to understand how the processes (e.g., annealing, ball-milling and severe plastic deformation) negatively affect the properties of $\mathrm{MH}$.

\section{AUTHOR CONTRIBUTIONS}

Both authors listed have made a substantial, direct, and intellectual contribution to the work, and approved it for publication.

Azeem, S., and Zain-ul-Abdein, M. (2012). Investigation of thermal conductivity enhancement in bakelite-graphite particulate filled polymeric composite. Int. J. Eng. Sci. 52, 30-40. doi: 10.1016/j.ijengsci.2011.12.002

Balakrishnan, S., Sofianos, M. V., Paskevicius, M., Rowles, M. R., and Buckley, C. E. (2020). Destabilised calcium hydride as a promising high-temperature thermal battery. J. Phys. Chem. C 124, 17512-17519.

Begeal, D. R. (1978). Hydrogen and deuterium permeation in copper alloys, copper-gold brazing alloys, gold, and the in situ growth of stable oxide permeation barriers. J. Vac. Sci. Technol. 15, 1146-1154.

Bérubé, V., Radtke, G., Dresselhaus, M., and Chen, G. (2007). Size effects on the hydrogen storage properties of nanostructured metal hydrides: a review. Int. J. Energy Res. 31, 637-663. doi: 10.1002/er.1284

Bird, J. E., Humphries, T. D., Paskevicius, M., Poupin, L., and Buckley, C. E. (2020). Thermal properties of thermochemical heat storage materials. Phys. Chem. Chem. Phys. 22, 4617-4625.

Birnbaum, H. (2003). Hydrogen effects on deformation and fracture: science and sociology. MRS Bull. 28, 479-485.

Birnbaum, H. K. (1987). "On the mechanisms of hydrogen related fracture in metals," in Environment Sensitive Fracture of Metals and Alloys, eds R. P. Wei, D. J. Duquette, T. W. Crooker, and A. J. Sedriks (Arlington, VA: Office of Naval Research), 105-113. 
Bloch, J. (1995). The temperature-dependent changes of the kinetics and morphology of hydride formation in zirconium. J. Alloys Compds. 216, 187-195. doi: 10.1016/0925-8388(94)01270-R

Bloch, J., and Mintz, M. H. (1997). Kinetics and mechanisms of metal hydrides formation-a review. J. Alloys Compds. 25, 529-541. doi: 10.1016/S09258388(96)03070-8

Bloch, J., Hadari, Z., and Mintz, M. H. (1984). The topochemistry of hydride formation in rare earth metals. J. Less Common Met. 102, 311-328. doi: 10.1016/ 0022-5088(84)90326-6

Borzone, E. M., Blanco, M. V., Baruj, A., and Meyer, G. O. (2014). Stability of $\mathrm{LaNi}_{5-\mathrm{x}} \mathrm{Sn}_{\mathrm{x}}$ cycled in hydrogen. Int. J. Hydrogen Energy 39, 8791-8796. doi: 10.1016/j.ijhydene.2013.12.031

Bououdina, M., Enoki, H., and Akiba, E. (1998). The investigation of the $\mathrm{Zr}_{1-\mathrm{y}} \mathrm{Ti}_{\mathrm{y}}\left(\mathrm{Cr}_{1-\mathrm{x}} \mathrm{Ni}_{\mathrm{x}}\right)_{2}-\mathrm{H}_{2}$ system $0.0 \leq \mathrm{y} \leq 1.0$ and $0.0 \leq \mathrm{x} \leq 1.0$ Phase composition analysis and thermodynamic properties. J. Alloys Compds. 281, 290-300. doi: 10.1016/S0925-8388(98)00792-0

Bououdina, M., Grant, D., and Walker, G. (2006). Review on hydrogen absorbing materials-structure, microstructure, and thermodynamic properties. Int. J. Hydrogen Energy 31, 177-182. doi: 10.1016/j.ijhydene.2005. 04.049

Bowman, R. C., Luo, C. H., Ahn, C. C., Witham, C. K., and Fultz, B. (1995). The effect of tin on the degradation of $\mathrm{LaNi}_{5} \mathrm{Sn}_{y}$ metal hydrides during thermal cycling. J. Alloys Compds. 217, 185-192. doi: 10.1016/0925-8388(94)01337-3

Broom, D. P. (2011). Hydrogen Storage Materials: The Characterisation of Their Storage Properties. London: Springer.

Buchner, H., and Povel, R. (1982). The daimler-benz hydride vehicle project. Int. J. Hydrogen Energy 7, 259-266. doi: 10.1016/0360-3199(82)90089-1

Chen, Z., Xiao, X., Chen, L., Fan, X., Liu, L., Li, S., et al. (2013). Development of Ti-Cr-Mn-Fe based alloys with high hydrogen desorption pressures for hybrid hydrogen storage vessel application. Int. J. Hydrogen Energy 38, 12803-12810. doi: 10.1016/j.ijhydene.2013.07.073

Cho, S.-W., Shim, G., Choi, G.-S., Park, C.-N., Yoo, J.-H., and Choi, J. (2007). Hydrogen absorption-desorption properties of $\mathrm{Ti}_{0.32} \mathrm{Cr}_{0.43} \mathrm{~V}_{0.25}$ alloy. J. Alloys Compds. 430, 136-141. doi: 10.1016/j.jallcom.2006.04.068

Choi, D., Wang, D., Viswanathan, V. V., Bae, I.-T., Wang, W., Nie, Z., et al. (2010). Li-ion batteries from $\mathrm{LiFePO}_{4}$ cathode and anatase/graphene composite anode for stationary energy storage. Electrochem. Commun. 12, 378-381. doi: 10.1016/j.elecom.2009.12.039

Corgnale, C., Hardy, B., Motyka, T., Zidan, R., Teprovich, J., and Peters, B. (2014). Screening analysis of metal hydride based thermal energy storage systems for concentrating solar power plants. Renew. Sustain. Energy Rev. 38, 821-833. doi: 10.1016/j.rser.2014.07.049

Corgnale, C., Motyka, T., Greenway, S., Perez-Berrios, J. M., Nakano, A., Ito, H., et al. (2013). Metal hydride bed system model for renewable source driven Regenerative Fuel Cell. J. Alloys Compds. 580, S406-S409. doi: 10.1016/j. jallcom.2013.03.010

Corré, S., Bououdina, M., Kuriyama, N., Fruchart, D., and Adachi, G. Y. (1999). Effects of mechanical grinding on the hydrogen storage and electrochemical properties of $\mathrm{LaNi}_{5}$. J. Alloys Compds. 292, 166-173. doi: 10.1016/S09258388(99)00084-5

Crivello, J.-C., and Gupta, M. (2003). Electronic properties of $\operatorname{lani}_{4.75} \mathrm{sn}_{0.25}$, lani $_{4.5} \mathrm{~m}_{0.5}\left(\mathrm{~m}=\mathrm{si}\right.$, ge, sn), lani ${ }_{4.5} \mathrm{sn}_{0.5} \mathrm{~h}_{5}$. J. Alloys Compds. 356, 151-155.

Curtis, R., and Chiotti, P. (1963). Thermodynamic properties of calcium hydride1. J. Phys. Chem. 67, 1061-1065.

Darras, C., Muselli, M., Poggi, P., Voyant, C., Hoguet, J. C., and Montignac, F. (2012). PV output power fluctuations smoothing: the MYRTE platform experience. Int. J. Hydrogen Energy 37, 14015-14025. doi: 10.1016/j.ijhydene. 2012.07.083

Davids, M. W., Lototskyy, M., Nechaev, A., Naidoo, Q., Williams, M., and Klochko, Y. (2011). Surface modification of TiFe hydrogen storage alloy by metalorganic chemical vapour deposition of palladium. Int. J. Hydrogen Energy 36, 9743-9750. doi: 10.1016/j.ijhydene.2011.05.036

Delhomme, B., Lanzini, A., Ortigoza-Villalba, G. A., Nachev, S., de Rango, P., Santarelli, M., et al. (2013). Coupling and thermal integration of a solid oxide fuel cell with a magnesium hydride tank. Int. J. Hydrogen Energy 38, 4740-4747. doi: 10.1016/j.ijhydene.2013.01.140

d'Entremont, A., Corgnale, C., Sulic, M., Hardy, B., Zidan, R., and Motyka, T. (2017). Modeling of a thermal energy storage system based on coupled metal hydrides (magnesium iron - sodium alanate) for concentrating solar power plants. Int. J. Hydrogen Energy 42, 22518-22529. doi: 10.1016/j.ijhydene.2017. 04.231

Dhaou, H., Askri, F., Ben Salah, M., Jemni, A., Ben Nasrallah, S., and Lamloumi, J. (2007). Measurement and modelling of kinetics of hydrogen sorption by $\mathrm{LaNi}_{5}$ and two related pseudobinary compounds. Int. J. Hydrogen Energy 32, 576-587. doi: 10.1016/j.ijhydene.2006.07.001

Dhaou, H., Souahlia, A., Mellouli, S., Askri, F., Jemni, A., and Ben Nasrallah, S. (2010). Experimental study of a metal hydride vessel based on a finned spiral heat exchanger. Int. J. Hydrogen Energy 35, 1674-1680. doi: 10.1016/j.ijhydene. 2009.11.094

dos Santos, D. S., Bououdina, M., and Fruchart, D. (2003). Structural and hydrogenation properties of an $80 \mathrm{wt} \% \mathrm{TiCr}_{1.1} \mathrm{~V}_{0.9}-20 \mathrm{wt} \% \mathrm{LaNi}_{5}$ composite material. Int. J. Hydrogen Energy 28, 1237-1241. doi: 10.1016/S0360-3199(03) 00006-5

Edalati, K., Matsuda, J., Iwaoka, H., Toh, S., Akiba, E., and Horita, Z. (2013). Highpressure torsion of TiFe intermetallics for activation of hydrogen storage at room temperature with heterogeneous nanostructure. Int. J. Hydrogen Energy 38, 4622-4627. doi: 10.1016/j.ijhydene.2013.01.185

Edalati, K., Matsuda, J., Yanagida, A., Akiba, E., and Horita, Z. (2014). Activation of TiFe for hydrogen storage by plastic deformation using groove rolling and high-pressure torsion: similarities and differences. Int. J. Hydrogen Energy 39, 15589-15594. doi: 10.1016/j.ijhydene.2014.07.124

Edalati, K., Matsuo, M., Emami, H., Itano, S., Alhamidi, A., Staykov, A., et al. (2016a). Impact of severe plastic deformation on microstructure and hydrogen storage of titanium-iron-manganese intermetallics. Scr. Mater. 124, 108-111. doi: 10.1016/j.scriptamat.2016.07.007

Edalati, K., Novelli, M., Itano, S., Li, H.-W., Akiba, E., Horita, Z., et al. (2018). Effect of gradient-structure versus uniform nanostructure on hydrogen storage of TiV-Cr alloys: investigation using ultrasonic SMAT and HPT processes. J. Alloys Compds. 737, 337-346. doi: 10.1016/j.jallcom.2017.12.053

Edalati, K., Shao, H., Emami, H., Iwaoka, H., Akiba, E., and Horita, Z. (2016b). Activation of titanium-vanadium alloy for hydrogen storage by introduction of nanograins and edge dislocations using high-pressure torsion. Int. J. Hydrogen Energy 41, 8917-8924. doi: 10.1016/j.ijhydene.2016.03.146

Emami, H., Edalati, K., Matsuda, J., Akiba, E., and Horita, Z. (2015). Hydrogen storage performance of TiFe after processing by ball milling. Acta Mater. 88, 190-195. doi: 10.1016/j.actamat.2014.12.052

Energy Reilly, J. J., and Wiswall, R. H. (1970). Higher hydrides of vanadium and niobium. Inorg. Chem. 9, 1678-1682.

Felderhoff, M., and Bogdanović, B. (2009). High temperature metal hydrides as heat storage materials for solar and related applications. Int. J. Mol. Sci. 10, 325-344.

Førde, T., Eriksen, J., Pettersen, A. G., Vie, P. J. S., and Ulleberg, Ø. (2009). Thermal integration of a metal hydride storage unit and a PEM fuel cell stack. Int. J. Hydrogen Energy 34, 6730-6739. doi: 10.1016/j.ijhydene.2009. 05.146

Friedlmeier, G., Manthey, A., Wanner, M., and Groll, M. (1995). Cyclic stability of various application-relevant metal hydrides. J. Alloys Compds. 231, 880-887. doi: 10.1016/0925-8388(95)01776-3

Fuel Cells Bulletin (2014). MYRTE hydrogen energy storage test powers up in Corsica. Fuel Cells Bull. 2014:8. doi: 10.1016/S1464-2859(14)70170-1

Fuel Cells Bulletin (2016a). Dutch partners deliver first 2 MW PEMFC plant, in China. Fuel Cells Bull. 2016:13. doi: 10.1016/S1464-2859(16)30329-7

Fuel Cells Bulletin (2016b). Switzerland unveils fuel cell powered heavy truck, and first hydroelectric hydrogen station. Fuel Cells Bull. 2016, 14-15. doi: 10.1016/ S1464-2859(16)30367-4

Fuel Cells Bulletin (2018a). Doosan sets foot in UAV fuel cell market. Fuel Cells Bull. 2018:6. doi: 10.1016/S1464-2859(18)30362-6

Fuel Cells Bulletin (2018b). Doosan starts installation of hydrogen-fueled $50 \mathrm{MW}$ fuel cell power plant in South Korea. Fuel Cells Bull. 2018:1. doi: 10.1016/S14642859(18)30270-0

Fujii, H., Munehiro, S., Fujii, K., and Orimo, S. (2002). Effect of mechanical grinding under $\mathrm{Ar}$ and $\mathrm{H}_{2}$ atmospheres on structural and hydriding properties in $\mathrm{LaNi}_{5}$. J. Alloys Compds. 33, 747-751. doi: 10.1016/S0925-8388(01)01508-0

Gahleitner, G. (2013). Hydrogen from renewable electricity: an international review of power-to-gas pilot plants for stationary applications. Int. J. Hydrogen Energy 38, 2039-2061. doi: 10.1016/j.ijhydene.2012.12.010 
Gangloff, R. P. (2003). Hydrogen Assisted Cracking of High Strength Alloys. Kensington, PA: Alcoa Technical Center.

Garrier, S., Chaise, A., de Rango, P., Marty, P., Delhomme, B., Fruchart, D., et al. (2011). $\mathrm{MgH}_{2}$ intermediate scale tank tests under various experimental conditions. Int. J. Hydrogen Energy 36, 9719-9726. doi: 10.1016/j.ijhydene.2011. 05.017

Goodell, P. D. (1984). Stability of rechargeable hydriding alloys during extended cycling. J. Less Common Met. 99, 1-14. doi: 10.1016/0022-5088(84)90330-8

Goodell, P. D., and Rudman, P. S. (1983). Hydriding and dehydriding rates of the $\mathrm{LaNi}_{5}-\mathrm{H}$ system. J. Less Common Met. 89, 117-125. doi: 10.1016/0022-5088(83) 90255-2

Gosselin, C., and Huot, J. (2019). First hydrogenation enhancement in TiFe alloys for hydrogen storage doped with yttrium. Metals 9:242.

Griessen, R., and Riesterer, T. (1988). "Heat of formation models," in Hydrogen in Intermetallic Compounds I, ed. L. Schlapbach (Berlin: Springer), 219-284.

Groll, M. (1993). Reaction beds for dry sorption machines. Heat Recov. Syst. CHP 13, 341-346. doi: 10.1016/0890-4332(93)90059-5

Hahne, E., and Kallweit, J. (1998). Thermal conductivity of metal hydride materials for storage of hydrogen: experimental investigation. Int. J. Hydrogen Energy 23, 107-114.

Haller, U. (1988). Untersuchung des Wärme-und Stofftransports in MetallhydridReaktionsbetten. Duesseldorf: VDI-Verlag.

Haraki, T., Oishi, K., Uchida, H., Miyamoto, Y., Abe, M., Kokaji, T., et al. (2008). Properties of hydrogen absorption by nano-structured FeTi alloys. Int. J. Mater Res. 99, 507-512. doi: 10.3139/146.101669

Hirscher, M., Yartys, V. A., Baricco, M., Bellosta von Colbe, J., Blanchard, D., Bowman, R. C., et al. (2020). Materials for hydrogen-based energy storage past, recent progress and future outlook. J. Alloys Compds. 827, 153548. doi: 10.1016/j.jallcom.2019.153548

Hongo, T., Edalati, K., Arita, M., Matsuda, J., Akiba, E., and Horita, Z. (2015). Significance of grain boundaries and stacking faults on hydrogen storage properties of $\mathrm{Mg}_{2} \mathrm{Ni}$ intermetallics processed by high-pressure torsion. Acta Mater. 92, 46-54. doi: 10.1016/j.actamat.2015.03.036

Hotta, H., Abe, M., Kuji, T., and Uchida, H. (2007). Synthesis of Ti-Fe alloys by mechanical alloying. J. Alloys Compds. 439, 221-226. doi: 10.1016/j.jallcom. 2006.05.137

Huot, J., Enoki, H., and Akiba, E. (2008). Synthesis, phase transformation, and hydrogen storage properties of ball-milled $\mathrm{TiV}_{0.9} \mathrm{Mn}_{1.1}$. J. Alloys Compds. 453, 203-209. doi: 10.1016/j.jallcom.2006.11.193

Hwang, J. J., and Chang, W. R. (2012). Characteristic study on fuel cell/battery hybrid power system on a light electric vehicle. J. Power Sources 207, 111-119. doi: 10.1016/j.jpowsour.2012.02.008

Iba, H., and Akiba, E. (1995). The relation between microstructure and hydrogen absorbing property in Laves phase-solid solution multiphase alloys. J. Alloys Compds. 231, 508-512. doi: 10.1016/0925-8388(95)01863-8

Iba, H., and Akiba, E. (1997). Hydrogen absorption and modulated structure in TiV-Mn alloys. J. Alloys Compds. 253-254, 21-24. doi: 10.1016/S0925-8388(96) 03072-1

Inui, H., Yamamoto, T., Hirota, M., and Yamaguchi, M. (2002). Lattice defects introduced during hydrogen absorption-desorption cycles and their effects on $\mathrm{P}-\mathrm{C}$ characteristics in some intermetallic compounds. J. Alloys Compds. 330-332, 117-124. doi: 10.1016/S0925-8388(01)01489-X

Ipsakis, D., Voutetakis, S., Seferlis, P., Stergiopoulos, F., and Elmasides, C. (2009). Power management strategies for a stand-alone power system using renewable energy sources and hydrogen storage. Int. J. Hydrogen Energy 34, 7081-7095. doi: 10.1016/j.ijhydene.2008.06.051

ISO (2004). Basic Considerations for the Safety of Hydrogen Systems. Geneva: International Organization for Standardization Publ.

ISO (2012). Gas Cylinders - Compatibility of Cylinder and Valve Materials with Gas Contents - Part 1: Metallic materials. Geneva: International Organization for Standardization Publ.

Ivanov, E., Konstanchuk, I., Stepanov, A., and Boldyrev, V. (1987). Magnesium mechanical alloys for hydrogen storage. J. Less Common Met. 131, 25-29. doi: 10.1016/0022-5088(87)90497-8

Jai-Young, L., Park, C. N., and Pyun, S. M. (1983). The activation processes and hydriding kinetics of FeTi. J. Less Common Met. 89, 163-168. doi: 10.1016/00225088(83)90262-X
Jehan, M., and Fruchart, D. (2013). McPhy-Energy's proposal for solid state hydrogen storage materials and systems. J. Alloys Compds. 580, S343-S348. doi: 10.1016/j.jallcom.2013.03.266

Jemni, A., Nasrallah, S. B., and Lamloumi, J. (1999). Experimental and theoretical study of ametal-hydrogen reactor. Int. J. Hydrogen Energy 24, 631-644. doi: 10.1016/S0360-3199(98)00117-7

Joubert, J. M., Černý, R., Latroche, M., Leroy, E., Guénée, L., Percheron-Guégan, A., et al. (2002). A Structural study of the homogeneity domain of $\mathrm{LaNi}_{5}$. J. Solid State Chem. 166, 1-6. doi: 10.1006/jssc.2001.9499

Joubert, J. M., Latroche, M., Černý, R., Bowman, R. C., Percheron-Guégan, A., and Yvon, K. (1999). Crystallographic study of $\mathrm{LaNi}_{5-x} \mathrm{Sn}_{x}(0.2 \leq \mathrm{x} \leq 0.5)$ compounds and their hydrides. J. Alloys Compds. 29, 124-129. doi: 10.1016/ S0925-8388(99)00311-4

Kan, A., Kang, L., Wang, C., and Cao, D. (2015). A simple and effective model for prediction of effective thermal conductivity of vacuum insulation panels. Future Cities Environ. 1:4.

Kao, Y.-F., Chen, S.-K., Sheu, J.-H., Lin, J.-T., Lin, W.-E., Yeh, J.-W., et al. (2010). Hydrogen storage properties of multi-principal-component $\mathrm{CoFeMnTi}_{x} \mathrm{~V}_{y} \mathrm{Zr}_{z}$ alloys. Int. J. Hydrogen Energy 35, 9046-9059. doi: 10.1016/j.ijhydene.2010.06. 012

Kim, K. J., Lloyd, G. M., Feldman, K. T., and Razani, A. (1998). Thermal analysis of the $\mathrm{Ca}_{0.4} \mathrm{Mm}_{0.6} \mathrm{Ni}_{5}$ metal-hydride reactor. Appl. Therm. Eng. 18, 1325-1336. doi: 10.1016/S1359-4311(98)00007-6

Kim, K. J., Montoya, B., Razani, A., and Lee, K. H. (2001). Metal hydride compacts of improved thermal conductivity. Int. J. Hydrogen Energy 26, 609-613. doi: 10.1016/S0360-3199(00)00115-4

Klebanoff, L. (2012). Hydrogen Storage Technology: Materials and Applications. Boca Raton, FL: CRC Press.

Kojima, Y., Kawai, Y., Towata, S. I., Matsunaga, T., Shinozawa, T., and Kimbara, M. (2006). Development of metal hydride with high dissociation pressure. J. Alloys Compds. 419, 256-261. doi: 10.1016/j.jallcom.2005.08.078

Kulshreshtha, S. K., Jayakumar, O. D., and Bhatt, K. B. (1993). Hydriding characteristics of palladium and platinum alloyed FeTi. J. Mater. Sci. 28, 4229-4233. doi: 10.1007/bf00351259

Kunce, I., Polanski, M., and Bystrzycki, J. (2013). Structure and hydrogen storage properties of a high entropy ZrTiVCrFeNi alloy synthesized using Laser Engineered Net Shaping (LENS). Int. J. Hydrogen Energy 38, 12180-12189. doi: 10.1016/j.ijhydene.2013.05.071

Kuriiwa, T., Tamura, T., Amemiya, T., Fuda, T., Kamegawa, A., Takamura, H., et al. (1999). New V-based alloys with high protium absorption and desorption capacity. J. Alloys Compds. 293-295, 433-436. doi: 10.1016/S0925-8388(99) 00325-4

Lai, Q., and Aguey-Zinsou, K.-F. (2018). Borohydrides as solid-state hydrogen storage materials: past, current approaches and future perspectives. Gen. Chem. 4:180017.

Lai, Q., Paskevicius, M., Sheppard, D. A., Buckley, C. E., Thornton, A. W., Hill, M. R., et al. (2015). Hydrogen storage materials for mobile and stationary applications: current state of the art. ChemSusChem 8, 2789-2825. doi: 10.1002/ cssc. 201500231

Lai, Q., Wang, T., Sun, Y., and Aguey-Zinsou, K.-F. (2018). Rational design of nanosized light elements for hydrogen storage: classes, synthesis, characterization, and properties. Adv. Mater. Technol. 3:1700298. doi: 10.1002/ admt.201700298

Lee, S. M., and Perng, T. P. (1991). Microstructural correlations with the hydrogenation kinetics of $\mathrm{FeTi}_{1+\xi}$ alloys. J. Alloys Compd. 177, 107-118. doi: 10.1016/0925-8388(91)90061-Y

Lévesque, S., Ciureanu, M., Roberge, R., and Motyka, T. (2000). Hydrogen storage for fuel cell systems with stationary applications- I. Transient measurement technique for packed bed evaluation. Int. J. Hydrogen Energy 25, 1095-1105. doi: 10.1016/S0360-3199(00)00023-9

Li, B., He, L., Li, J., Li, H.-W., Lu, Z., and Shao, H. (2019). Ti-V-C-based alloy with a FCC Lattice Structure for Hydrogen Storage. Molecules 24:552.

Li, B., Li, J., Shao, H., Li, W., and Lin, H. (2018). Synthesis, morphology, and hydrogen absorption properties of TiVMn and TiCrMn nanoalloys with a FCC structure. Scanning 2018, 1-9. doi: 10.1155/2018/5906473

Li, L., Akiyama, T., and Yagi, J. I. (1999). Reaction mechanism of hydriding combustion synthesis of $\mathrm{Mg}_{2} \mathrm{NiH}_{4}$. Intermetallics 7, 671-677. doi: 10.1016/ S0966-9795(98)00082-X 
Liang, G., Huot, J., and Schulz, R. (2001a). Hydrogen storage properties of the mechanically alloyed $\mathrm{LaNi}_{5}$-based materials. J. Alloys Compds. 320, 133-139. doi: 10.1016/S0925-8388(01)00929-X

Liang, G., Huot, J., and Schulz, R. (2001b). Mechanical alloying and hydrogen storage properties of $\mathrm{CaNi}_{5}$-based alloys. J. Alloys Compds. 321, 146-150. doi: 10.1016/S0925-8388(01)01010-6

Lias, I. B., Azaiauddin, A. M. M., Ismail, M. H., and Mamat, M. A. I. (2016). Thermal conductivity and microstructure of aluminum foam tube produce (AFTP) using infiltration method with vacuum-gas. Imp. J. Interdiscip. Res. 3, 1843-1848.

Liu, F. J., and Suda, S. (1995). Properties and characteristics of fluorinated hydriding alloys. J. Alloys Compds. 231, 742-750. doi: 10.1016/0925-8388(95) 01711-9

Liu, H., Naumov, I. I., Hoffmann, R., Ashcroft, N., and Hemley, R. J. (2017). Potential high- $\mathrm{T}_{c}$ superconducting lanthanum and yttrium hydrides at high pressure. Proc. Natl. Acad. Sci. U.S.A. 114, 6990-6995.

Liu, Y., Pan, H., Gao, M., and Wang, Q. (2011). Advanced hydrogen storage alloys for Ni/MH rechargeable batteries. J. Mater. Chem. 21, 4743-4755. doi: 10.1039/C0JM01921F

Lototsky, M. V., Yartys, V. A., and Zavaliy, I. Y. (2005). Vanadium-based BCC alloys: phase-structural characteristics and hydrogen sorption properties. J. Alloys Compds. 404-406, 421-426. doi: 10.1016/j.jallcom.2005.01.139

Lototskyy, M. V., Tolj, I., Pickering, L., Sita, C., Barbir, F., and Yartys, V. (2017). The use of metal hydrides in fuel cell applications. Prog. Nat. Sci. 27, 3-20. doi: 10.1016/j.pnsc.2017.01.008

Louthan, M. Jr., and Derrick, R. (1975). Hydrogen transport in austenitic stainless steel. Corros. Sci. 15, 565-577.

Louthan, M. Jr., Donovan, J., and Caskey, G. Jr. (1975). Hydrogen diffusion and trapping in nickel. Acta Metall. 23, 745-749.

Luo, S., Clewley, J. D., Flanagan, T. B., Bowman, R. C., and Wade, L. A. (1998). Further studies of the isotherms of $\mathrm{LaNi}_{5-x} \mathrm{Sn}_{x}-\mathrm{H}$ for $\mathrm{x}=0-0.5$. J. Alloys Compds. 267, 171-181. doi: 10.1016/S0925-8388(97)00536-7

Lv, P., and Huot, J. (2017). Hydrogenation improvement of TiFe by adding $\mathrm{ZrMn}_{2}$. Energy 138, 375-382. doi: 10.1016/j.energy.2017.07.072

MacDonald, B. D., and Rowe, A. M. (2006). A thermally coupled metal hydride hydrogen storage and fuel cell system. J. Power Sources 161, 346-355. doi: 10.1016/j.jpowsour.2006.04.018

Manickam, K., Mistry, P., Walker, G., Grant, D., Buckley, C. E., Humphries, T. D., et al. (2019). Future perspectives of thermal energy storage with metal hydrides. Int. J. Hydrogen Energy 44, 7738-7745.

Manna, J., Tougas, B., and Huot, J. (2018). Mechanical activation of air exposed $\mathrm{TiFe}+4 \mathrm{wt} \% \mathrm{Zr}$ alloy for hydrogenation by cold rolling and ball milling. Int. J. Hydrogen Energy 43, 20795-20800. doi: 10.1016/j.ijhydene.2018.09.096

Martin, M., Gommel, C., Borkhart, C., and Fromm, E. (1996). Absorption and desorption kinetics of hydrogen storage alloys. J. Alloys Compds. 238, 193-201. doi: 10.1016/0925-8388(96)02217-7

Mazzucco, A., and Rokni, M. (2015). Generalized computational model for highpressure metal hydrides with variable thermal properties. Int. J. Hydrogen Energy 40, 11470-11477. doi: 10.1016/j.ijhydene.2015.03.032

Mazzucco, A., Dornheim, M., Sloth, M., Jensen, T. R., Jensen, J. O., and Rokni, M. (2014). Bed geometries, fueling strategies and optimization of heat exchanger designs in metal hydride storage systems for automotive applications: a review. Int. J. Hydrogen Energy 39, 17054-17074. doi: 10.1016/j.ijhydene.2014.08.047

Mellouli, S., Askri, F., Dhaou, H., Jemni, A., and Ben Nasrallah, S. (2007). A novel design of a heat exchanger for a metal-hydrogen reactor. Int. J. Hydrogen Energy 32, 3501-3507. doi: 10.1016/j.ijhydene.2007.02.039

Mellouli, S., Dhaou, H., Askri, F., Jemni, A., and Nasrallah, S. B. (2009). Hydrogen storage in metal hydride tanks equipped with metal foam heat exchanger. Int. J. Hydrogen Energy 34, 9393-9401.

Melnichuk, M., Silin, N., and Peretti, H. A. (2009). Optimized heat transfer fin design for a metal-hydride hydrogen storage container. Int. J. Hydrogen Energy 34, 3417-3424. doi: 10.1016/j.ijhydene.2009.02.040

Miedema, A. R., de Boer, F. R., and Boom, R. (1977). Model predictions for the enthalpy of formation of transition metal alloys. Calphad 1, 341-359. doi: 10.1016/0364-5916(77)90011-6

Miller, A. R., and Barnes, D. L. (2002). "Advanced underground vehicle power and control fuel cell mine locomotive," in Proceedings of the 2002 US DOE Hydrogen Program Review NREL/CP-610-32405, Golden, CO.
Mintz, M. H., and Bloch, J. (1985). Evaluation of the kinetics and mechanisms of hybriding reactions. Prog. Solid State Chem. 16, 163-194. doi: 10.1016/00796786(85)90004-4

Mintz, M. H., Vaknin, S., Biderman, S., and Hadari, Z. (1981). Hydrides of ternary $\mathrm{TiFe}_{x} \mathrm{M}_{1-x}(\mathrm{M}=\mathrm{Cr}, \mathrm{Mn}, \mathrm{Co}, \mathrm{Ni})$ intermetallics. J. Appl. Phys. 52, 463-467. doi: $10.1063 / 1.329808$

Miraglia, S., de Rango, P., Rivoirard, S., Fruchart, D., Charbonnier, J., and Skryabina, N. (2012). Hydrogen sorption properties of compounds based on BCC $\mathrm{Ti}_{1-x} \mathrm{~V}_{1-y} \mathrm{Cr}_{1+x+y}$ alloys. J. Alloys Compds. 536, 1-6. doi: 10.1016/j. jallcom.2012.05.008

Mohammadshahi, S., Gray, E. M., and Webb, C. (2016). A review of mathematical modelling of metal-hydride systems for hydrogen storage applications. Int. J. Hydrogen Energy 41, 3470-3484.

Mori, D., Kobayashi, N., Shinozawa, T., Matsunaga, T., Kubo, H., Toh, K., et al. (2005). Hydrogen storage materials for fuel cell vehicles high-pressure $\mathrm{MH}$ system. J. Jpn. Inst. Met. 69, 308-311. doi: 10.2320/jinstmet.69.308

Nagel, M., Komazaki, Y., and Suda, S. (1986). Effective thermal conductivity of a metal hydride bed augmented with a copper wire matrix. J. Less Common Met. 120, 35-43. doi: 10.1016/0022-5088(86)90625-9

Nasako, K., Ito, Y., Hiro, N., and Osumi, M. (1998). Stress on a reaction vessel by the swelling of a hydrogen absorbing alloy. J. Alloys Compds. 264, 271-276.

Nelson, H. G., and Stein, J. E. (1973). Gas-Phase Hydrogen Permeation through Alpha Iron, 4130 Steel, and 304 Stainless Steel from Less than 100 C to near 600 C. Moffett Field, CA: NASA.

Nishimiya, N., Wada, T., Matsumoto, A., and Tsutsumi, K. (2000). Hydriding characteristics of zirconium-substituted FeTi. J. Alloys Compds. 313, 53-58. doi: 10.1016/S0925-8388(00)01181-6

Okada, M., Kuriiwa, T., Tamura, T., Takamura, H., and Kamegawa, A. (2002). Ti-V-Cr b.c.c. alloys with high protium content. J. Alloys Compds. 330-332, 511-516. doi: 10.1016/S0925-8388(01)01647-4

Orimo, S. I., and Fujii, H. (1998). Effects of nanometer-scale structure on hydriding properties of Mg-Ni alloys: a review. Intermetallics 6, 185-192. doi: 10.1016/ S0966-9795(97)00064-2

Orimo, S., Züttel, A., Ikeda, K., Saruki, S., Fukunaga, T., Fujii, H., et al. (1999). Hydriding properties of the MgNi-based systems. J. Alloys Compds. 293-295, 437-442. doi: 10.1016/S0925-8388(99)00327-8

Parra, D., Valverde, L., Pino, F. J., and Patel, M. K. (2019). A review on the role, cost and value of hydrogen energy systems for deep decarbonisation. Renew. Sustain. Energy Rev. 101, 279-294. doi: 10.1016/j.rser.2018.11.010

Pasini, J. M., Corgnale, C., van Hassel, B. A., Motyka, T., Kumar, S., and Simmons, K. L. (2013). Metal hydride material requirements for automotive hydrogen storage systems. Int. J. Hydrogen Energy 38, 9755-9765. doi: 10.1016/j.ijhydene. 2012.08.112

Pelay, U., Luo, L., Fan, Y., Stitou, D., and Rood, M. (2017). Thermal energy storage systems for concentrated solar power plants. Renew. Sustain. Energy Rev. 79, 82-100. doi: 10.1016/j.rser.2017.03.139

Pickering, L., Lototskyy, M. V., Wafeeq Davids, M., Sita, C., and Linkov, V. (2018). Induction melted $\mathrm{AB}_{2}$-type metal hydrides for hydrogen storage and compression applications. Mater. Today Proc. 5(4, Part 2), 10470-10478. doi: 10.1016/j.matpr.2017.12.378

Poupin, L., Humphries, T. D., Paskevicius, M., and Buckley, C. E. (2020). An experimental high temperature thermal battery coupled to a low temperature metal hydride for solar thermal energy storage. Sustain. Energy Fuels 4, 285 292.

Qin, F., Guo, L., Chen, J., and Chen, Z. (2008). Pulverization, expansion of La0. 6Y0. 4Ni4. 8Mn0. 2 during hydrogen absorption-desorption cycles and their influences in thin-wall reactors. Int. J. Hydrogen Energy 33, 709-717.

Quijano, R., de Coss, R., and Singh, D. J. (2009). Electronic structure and energetics of the tetragonal distortion for $\mathrm{TiH}_{2}, \mathrm{ZrH}_{2}$, and $\mathrm{HfH}_{2}$ : a first-principles study. Phys. Rev. B 80:184103.

Reilly, J., and Wiswall, R. (1974). Formation and properties of iron titanium hydride. Inorg. Chem. 13, 218-222.

Rizzi, P., Pinatel, E., Luetto, C., Florian, P., Graizzaro, A., Gagliano, S., et al. (2015). Integration of a PEM fuel cell with a metal hydride tank for stationary applications. J. Alloys Compds. 645, S338-S342. doi: 10.1016/j.jallcom.2014.12. 145

Rudman, P. S. (1983). Hydriding and dehydriding kinetics. J. Less Common Met. 89, 93-110. doi: 10.1016/0022-5088(83)90253-9 
Rusman, N., and Dahari, M. (2016). A review on the current progress of metal hydrides material for solid-state hydrogen storage applications. Int. J. Hydrogen Energy 41, 12108-12126.

Sahlberg, M., Karlsson, D., Zlotea, C., and Jansson, U. (2016). Superior hydrogen storage in high entropy alloys. Sci. Rep. 6:36770. doi: 10.1038/srep36770

Saita, I., Sato, M., Uesugi, H., and Akiyama, T. (2007). Hydriding combustion synthesis of TiFe. J. Alloys Compds. 446-447, 195-199. doi: 10.1016/j.jallcom. 2007.02.150

Sakintuna, B., Lamari-Darkrim, F., and Hirscher, M. (2007). Metal hydride materials for solid hydrogen storage: a review. Int. J. Hydrogen Energy 32, 1121-1140. doi: 10.1016/j.ijhydene.2006.11.022

Sandrock, G. (1997). State-of-the-Art Review of Hydrogen Storage in Reversible Metal Hydrides for Military Fuel Cell Applications. Fort Belvoir, VA: SUNATECH INC.

Sandrock, G. (1999). A panoramic overview of hydrogen storage alloys from a gas reaction point of view. J. Alloys Compds. 293-295, 877-888. doi: 10.1016/S09258388(99)00384-9

Sandrock, G., Goodell, P., Huston, E., and Golben, P. (1989). On the disproportionation of intermetallic hydrides. Z. Phys. Chem. 164, 1285-1290.

Santos, S., Costa, A., De Castro, J., dos Santos, D. S., Botta Filho, W. J., and Ishikawa, T. T. (2004). Mechanical and reactive milling of a TiCrV BCC solid solution. J. Metastab. Nanocryst. Mater. 20-21, 291-296.

Satya Sekhar, B., Lototskyy, M., Kolesnikov, A., Moropeng, M. L., Tarasov, B. P., and Pollet, B. G. (2015). Performance analysis of cylindrical metal hydride beds with various heat exchange options. J. Alloys Compds. 645, S89-S95. doi: 10.1016/j.jallcom.2014.12.272

Schlapbach, L., and Riesterer, T. (1983). The activation of FeTi for hydrogen absorption. Appl. Phys. A 32, 169-182. doi: 10.1007/bf00820257

Schlapbach, L., Seiler, A., Stucki, F., and Siegmann, H. C. (1980). Surface effects and the formation of metal hydrides. J. Less Common Met. 73, 145-160. doi: 10.1016/0022-5088(80)90354-9

Schober, T., and Westlake, D. G. (1981). The activation of FeTi for hydrogen storage: a different view. Scr. Metall. 15, 913-918. doi: 10.1016/0036-9748(81) 90277-5

Schoenung, S. (2010). "<Task-18-Final-Report-Phase-2.pdf>". Paris: IEA.

Selvaraj, S., Jain, A., Kumar, S., Zhang, T., Isobe, S., Miyaoka, H., et al. (2018). Study of cyclic performance of $\mathrm{V}$-Ti-Cr alloys employed for hydrogen compressor. Int. J. Hydrogen Energy 43, 2881-2889. doi: 10.1016/j.ijhydene.2017.12.159

Seo, C.-Y., Kim, J.-H., Lee, P. S., and Lee, J.-Y. (2003). Hydrogen storage properties of vanadium-based b.c.c. solid solution metal hydrides. J. Alloys Compd. 348, 252-257. doi: 10.1016/S0925-8388(02)00831-9

Shafiee, S., and McCay, M. H. (2016). Different reactor and heat exchanger configurations for metal hydride hydrogen storage systems - A review. Int. J. Hydrogen Energy 41, 9462-9470. doi: 10.1016/j.ijhydene.2016.03.133

Shen, C. C., and Perng, T. P. (2005). On the cyclic hydrogenation stability of an $\mathrm{Lm}(\mathrm{NiAl})_{5}$-based alloy with different hydrogen loadings. J. Alloys Compd. 392, 187-191. doi: 10.1016/j.jallcom.2004.09.015

Shen, C.-C., and Li, H.-C. (2015). Cyclic hydrogenation stability of $\gamma$-hydrides for $\mathrm{Ti}_{25} \mathrm{~V}_{35} \mathrm{Cr}_{40}$ alloys doped with carbon. J. Alloys Compd. 648, 534-539. doi: 10.1016/j.jallcom.2015.07.021

Sheppard, D. A., Paskevicius, M., Humphries, T. D., Felderhoff, M., Capurso, G., von Colbe, J. B., et al. (2016). Metal hydrides for concentrating solar thermal power energy storage. Appl. Phys. A 122:395.

Sheppard, D. A., Paskevicius, M., Javadian, P., Davies, I. J., and Buckley, C. E. (2019). Methods for accurate high-temperature Sieverts-type hydrogen measurements of metal hydrides. J. Alloys Compd. 787, 1225-1237. doi: 10. 1016/j.jallcom.2019.02.067

Shibuya, M., Nakamura, J., and Akiba, E. (2008). Hydrogenation properties and microstructure of Ti-Mn-based alloys for hybrid hydrogen storage vessel. J. Alloys Compd. 466, 558-562. doi: 10.1016/j.jallcom.2007.11.120

Singh, A., Singh, B. K., Davidson, D. J., and Srivastava, O. N. (2004). Studies on improvement of hydrogen storage capacity of $\mathrm{AB}_{5}$ type: $\mathrm{MmNi}_{4.6} \mathrm{Fe}_{0.4}$ alloy. Int. J. Hydrogen Energy 29, 1151-1156. doi: 10.1016/j.ijhydene.2003.10.014

Sofianos, M. V., Randall, S., Paskevicius, M., Aguey-Zinsou, K.-F., Rowles, M. R., Humphries, T. D., et al. (2020). Exploring halide destabilised calcium hydride as a high-temperature thermal battery. J. Alloys Compd. 819:153340. doi: 10.1016/ j.jallcom.2019.153340

Song, M. Y., Ivanov, E., Darriet, B., Pezat, M., and Hagenmuller, P. (1987). Hydriding and dehydriding characteristics of mechanically alloyed mixtures Mg-xwt.\%Ni (x = 5, 10, 25 and 55). J. Less Common Met. 131, 71-79. doi: 10.1016/0022-5088(87)90502-9

Song, W., Du, J., Xu, Y., and Long, B. (1997). A study of hydrogen permeation in aluminum alloy treated by various oxidation processes. J. Nucl. Mater. 246, 139-143.

Stepanov, A., Ivanov, E., Konstanchuk, I., and Boldyrev, V. (1987). Hydriding properties of mechanical alloys Mg-Ni. J. Less Common Met. 131, 89-97. doi: 10.1016/0022-5088(87)90504-2

Suda, S. (1985). Recent development of hydride energy systems in Japan. Int. J. Hydrogen Energy 10, 757-765. doi: 10.1016/0360-3199(85)90112-0

Suda, S., Kobayashi, N., Yoshida, K., Ishido, Y., and Ono, S. (1980). Experimental measurements of thermal conductivity. J. Less Common Met. 74, $127-136$.

Suda, S., Komazaki, Y., and Kobayashi, N. (1983). Effective thermal conductivity of metal hydride beds. J. Less Common Met. 89, 317-324.

Suda, S., Sun, Y. M., Liu, B. H., Zhou, Y., Morimitsu, S., Arai, K., et al. (2001). Catalytic generation of hydrogen by applying fluorinated-metal hydrides as catalysts. Appl. Phys. A 72, 209-212. doi: 10.1007/s003390100785

Suda, T., Ohkawa, M., Sawada, S., Watanabe, S., Ohnuki, S., and Nagata, S. (2002). Effect of surface modification by ion implantation on hydrogenation property of TiFe alloy. Mater. Trans. 43, 2703-2705.

Sugimoto, S., Maeda, T., Book, D., Kagotani, T., Inomata, K., Homma, M., et al. (2002). GHz microwave absorption of a fine $\alpha$-Fe structure produced by the disproportionation of $\mathrm{Sm}_{2} \mathrm{Fe}_{17}$ in hydrogen. J. Alloys Compd. 330-332, 301-306. doi: 10.1016/S0925-8388(01)01504-3

Sun, Y., Shen, C., Lai, Q., Liu, W., Wang, D.-W., and Aguey-Zinsou, K.-F. (2018). Tailoring magnesium based materials for hydrogen storage through synthesis: current state of the art. Energy Storage Mater. 10, 168-198. doi: 10.1016/j.ensm. 2017.01.010

Suwarno, S., Gosselin, Y., Solberg, J., Maehlen, J., Williams, M., Krogh, B., et al. (2012). Selective hydrogen absorption from gaseous mixtures by BCC Ti-V alloys. Int. J. Hydrogen Energy 37, 4127-4138.

Takeichi, N., Senoh, H., Takeshita, H. T., Oishi, T., Tanaka, H., Kiyobayashi, T., et al. (2004). Hydrogenation properties and structure of $\mathrm{Ti}-\mathrm{Cr}$ alloy prepared by mechanical grinding. Mat. Sci. Eng. B 108, 100-104. doi: 10.1016/j.mseb.2003. 10.057

Takeichi, N., Senoh, H., Yokota, T., Tsuruta, H., Hamada, K., Takeshita, H. T., et al. (2003). "Hybrid hydrogen storage vessel", a novel high-pressure hydrogen storage vessel combined with hydrogen storage material. Int. J. Hydrogen Energy 28, 1121-1129. doi: 10.1016/S0360-3199(02)00216-1

Tarasov, B. P., Bocharnikov, M. S., Yanenko, Y. B., Fursikov, P. V., and Lototskyy, M. V. (2018). Cycling stability of RNi5 ( $\mathrm{R}=\mathrm{La}, \mathrm{La}+\mathrm{Ce})$ hydrides during the operation of metal hydride hydrogen compressor. Int. J. Hydrogen Energy 43, 4415-4427.

Terashita, N., Takahashi, M., Kobayashi, K., Sasai, T., and Akiba, E. (1999). Synthesis and hydriding/dehydriding properties of amorphous $\mathrm{Mg}_{2} \mathrm{Ni}_{1.9} \mathrm{M}_{0.1}$ alloys mechanically alloyed from $\mathrm{Mg}_{2} \mathrm{Ni}_{0.9} \mathrm{M}_{0.1}$ ( $\mathrm{M}=$ none, $\mathrm{Ni}, \mathrm{Ca}, \mathrm{La}, \mathrm{Y}, \mathrm{Al}, \mathrm{Si}$, $\mathrm{Cu}$ and $\mathrm{Mn}$ ) and Ni powder. J. Alloys Compd. 293-295, 541-545. doi: 10.1016/ S0925-8388(99)00408-9

Tetuko, A. P., Shabani, B., and Andrews, J. (2016). Thermal coupling of PEM fuel cell and metal hydride hydrogen storage using heat pipes. Int. J. Hydrogen Energy 41, 4264-4277. doi: 10.1016/j.ijhydene.2015.12.194

ToolBox, E. (2003). Thermal Conductivity of selected Materials and Gases. Available online at: https://www.engineeringtoolbox.com/thermal-conductivity-d_429. html (accessed October 10, 2020).

Towata, S. I., Noritake, T., Itoh, A., Aoki, M., and Miwa, K. (2013). Effect of partial niobium and iron substitution on short-term cycle durability of hydrogen storage Ti-Cr-V alloys. Int. J. Hydrogen Energy 38, 3024-3029. doi: 10.1016/ j.ijhydene.2012.12.100

Trudeau, M. L., Dignard-Bailey, L., Schulz, R., Tessier, P., Zaluski, L., Ryan, D. H., et al. (1992). The oxidation of nanocrystalline FeTi hydrogen storage compounds. Nanostruct. Mater. 1, 457-464. doi: 10.1016/0965-9773(92)90 078-C 
Uchida, H. H., Wulz, H. G., and Fromm, E. (1991). Catalytic effect of nickel, iron and palladium on hydriding titanium and storage materials. J. Less Common Met. 172-174, 1076-1083. doi: 10.1016/S0022-5088(06)80015-9

Valera-Medina, A., Xiao, H., Owen-Jones, M., David, W. I. F., and Bowen, P. J. (2018). Ammonia for power. Prog. Energy Combust. Sci. 69, 63-102. doi: 10. 1016/j.pecs.2018.07.001

Van Vucht, J., Kuijpers, F., and Bruning, H. (1970). Reversible room-temperature absorption of large quantities of hydrogen by intermetallic compounds. Philips Res. Rep. 25, 133-140.

Vega, L. E. R., Leiva, D. R., Leal Neto, R. M., Silva, W. B., Silva, R. A., Ishikawa, T. T., et al. (2018). Mechanical activation of TiFe for hydrogen storage by cold rolling under inert atmosphere. Int. J. Hydrogen Energy 43, 2913-2918. doi: 10.1016/j.ijhydene.2017.12.054

Völkl, J., and Alefeld, G. (1975). Diffusion in Solids, eds A. S. Nowick and J. J. Burton (New York, NY: Academic Press).

von Helmolt, R., and Eberle, U. (2007). Fuel cell vehicles: status 2007. J. Power Sources 165, 833-843. doi: 10.1016/j.jpowsour.2006.12.073

Wakao, N., and Vortmeyer, D. (1971). Pressure dependency of effective thermal conductivity of packed beds. Chem. Eng. Sci. 26, 1753-1765. doi: 10.1016/00092509(71)86063-3

Walker, G. (2008). Solid-state hydrogen storage: materials and chemistry. Elsevier.

Wang, J.-Y., Jeng, R.-R., Nieh, J.-K., Lee, S., Lee, S.-L., and Bor, H.-Y. (2007). Comparing the hydrogen storage alloys- $\mathrm{TiCrV}$ and vanadium-rich $\mathrm{TiCrMnV}$. Int. J. Hydrogen Energy 32, 3959-3964. doi: 10.1016/j.ijhydene.2007.05.025

Wang, M., Sun, W., Sha, C., Hu, B., Du, Y., Sun, L., et al. (2012). Thermodynamic Modeling of the Li-H and Ca-H Systems. J. Phase Equilibria Diffus. 33, 89-96.

Wang, X. L., and Suda, S. (1995). Surface characteristics of fluorinated hydriding alloys. J. Alloys Compd. 231, 380-386. doi: 10.1016/0925-8388(95)01851-4

Wang, Y., Adroher, X. C., Chen, J., Yang, X. G., and Miller, T. (2009). Threedimensional modeling of hydrogen sorption in metal hydride hydrogen storage beds. J. Power Sources 194, 997-1006.

Wu, H., Grabarnik, S., Emadi, A., De Graaf, G., and Wolffenbuttel, R. (2009). Characterization of thermal cross-talk in a MEMS-based thermopile detector array. J. Micromech. Microeng. 19:074022.

Xiukui, S., Jian, X., and Yiyi, L. (1989). Hydrogen permeation behaviour in austenitic stainless steels. Mater. Sci. Eng. A 114, 179-187.

Yang, F., Cao, X., Zhang, Z., Bao, Z., Wu, Z., and Serge, N. N. (2012). Assessment on the Long Term Performance of $\mathrm{LaNi}_{5}$ based Hydrogen Storage System. Energy Procedia 29, 720-730. doi: 10.1016/j.egypro.2012.09.084

Yartys, V. A., Lototskyy, M. V., Akiba, E., Albert, R., Antonov, V. E., Ares, J. R., et al. (2019). Magnesium based materials for hydrogen based energy storage: Past, present and future. Int. J. Hydrogen Energy 44, 7809-7859. doi: 10.1016/j. ijhydene.2018.12.212

Yu, X. B., Wu, Z., Xia, B. J., and Xu, N. X. (2004). Enhancement of hydrogen storage capacity of Ti-V-Cr-Mn BCC phase alloys. J. Alloys Compd. 372, 272-277. doi: $10.1016 /$ j.jallcom.2003.09.153
Yu, X. B., Yang, Z. X., Feng, S. L., Wu, Z., and Xu, N. X. (2006). Influence of $\mathrm{Fe}$ addition on hydrogen storage characteristics of Ti-V-based alloy. Int. J. Hydrogen Energy 31, 1176-1181. doi: 10.1016/j. ijhydene.2005.09.008

Zaluski, L., Zaluska, A., Tessier, P., Ström-Olsen, J. O., and Schulz, R. (1995a). Catalytic effect of Pd on hydrogen absorption in mechanically alloyed $\mathrm{Mg}_{2} \mathrm{Ni}$, LaNi5 and FeTi. J. Alloys Compd. 217, 295-300. doi: 10.1016/0925-8388(94) 01358-6

Zaluski, L., Zaluska, A., Tessier, P., Ström-Olsen, J. O., and Schulz, R. (1995b). Effects of relaxation on hydrogen absorption in Fe-Ti produced by ball-milling. J. Alloys Compd. 227, 53-57. doi: 10.1016/0925-8388(95)01623-6

Zepon, G., Leiva, D. R., Strozi, R. B., Bedoch, A., Figueroa, S. J. A., Ishikawa, T. T., et al. (2018). Hydrogen-induced phase transition of $\mathrm{MgZrTiFe}_{0.5} \mathrm{Co}_{0.5} \mathrm{Ni}_{0.5}$ high entropy alloy. Int. J. Hydrogen Energy 43, 1702-1708. doi: 10.1016/j. ijhydene.2017.11.106

Zhang, R. F., Zhang, S. H., He, Z. J., Jing, J., and Sheng, S. H. (2016). Miedema Calculator: A thermodynamic platform for predicting formation enthalpies of alloys within framework of Miedema's Theory. Comput. Phys. Commun. 209, 58-69. doi: 10.1016/j.cpc.2016.08.013

Zhang, Y., and Zhou, Y. J. (2007). Solid solution formation criteria for high entropy alloys. Mater. Sci. Forum 561-565, 1337-1339. doi: 10.4028/www.scientific.net/ msf.561-565.1337

Ziogou, C., Ipsakis, D., Elmasides, C., Stergiopoulos, F., Papadopoulou, S., Seferlis, P., et al. (2011). Automation infrastructure and operation control strategy in a stand-alone power system based on renewable energy sources. J. Power Sources 196, 9488-9499. doi: 10.1016/j.jpowsour.2011.07.029

Züchner, H., and Kirch, G. (1984). Auger electron spectroscopy investigation of the activation of TiFe for hydrogen uptake. J. Less Common Met. 99, 143-150. doi: 10.1016/0022-5088(84)90344-8

Züttel, A. (2003). Materials for hydrogen storage. Mater. Today 6, 24-33. doi: 10.1016/S1369-7021(03)00922-2

Züttel, A., Remhof, A., Borgschulte, A., and Friedrichs, O. (2010). Hydrogen: the future energy carrier. Philos. Trans. A Math. Phys. Eng. Sci. 368, 3329-3342. doi: $10.1098 /$ rsta.2010.0113

Conflict of Interest: The authors declare that the research was conducted in the absence of any commercial or financial relationships that could be construed as a potential conflict of interest.

Copyright (c) 2021 Modi and Aguey-Zinsou. This is an open-access article distributed under the terms of the Creative Commons Attribution License (CC BY). The use, distribution or reproduction in other forums is permitted, provided the original author(s) and the copyright owner(s) are credited and that the original publication in this journal is cited, in accordance with accepted academic practice. No use, distribution or reproduction is permitted which does not comply with these terms. 